\title{
Effects of rheumatoid arthritis associated transcriptional changes on osteoclast differentiation network in the synovium
}

\author{
Shilpa Harshan ${ }^{1}$, Poulami Dey ${ }^{1,2}$, Srivatsan Ragunathan ${ }^{\text {Corresp. }} 1$ \\ 1 Institute of Bioinformatics and Applied Biotechnology, Bangalore, Karnataka, India \\ 2 Manipal Academy of Higher Education, Manipal, Karnataka, India \\ Corresponding Author: Srivatsan Ragunathan \\ Email address: srivatsan@ibab.ac.in
}

Background. Osteoclast differentiation in the inflamed synovium of rheumatoid arthritis affected joints leads to the formation of bone lesions. Reconstruction and analysis of protein interaction networks underlying specific disease phenotypes are essential for designing therapeutic interventions. In this study we have created a network that captures signal flow leading to osteoclast differentiation. Based on transcriptome analysis, we have indicated the potential mechanisms responsible for the phenotype in the rheumatoid arthritis affected synovium.

Method. We collected information on gene expression, pathways and protein interactions related to rheumatoid arthritis from literature and databases namely Gene Expression Omnibus, KEGG pathway and STRING. Based on these information, we created a network for the differentiation of osteoclasts. We identified the differentially regulated network genes and reported the signaling that are responsible for the process in the rheumatoid arthritis affected synovium.

Result. Our network reveals the mechanisms underlying the activation of the Neutrophil Cytosolic Factor complex in connection to osteoclastogenesis in rheumatoid arthritis. Additionally, the study reports the predominance of the canonical pathway of NF-kB activation in the diseased synovium. The network also confirms that the upregulation of $T$ cell receptor signaling and downregulation of TGF $\beta$ signaling pathway favour osteoclastogenesis in Rheumatoid Arthritis. To the best of our knowledge, this is the first comprehensive protein-protein interaction network describing Rheumatoid Arthritis driven osteoclastogenesis in the synovium.

Discussion. This study provides information that can be used to build models of the signal flow involved in the process of osteoclast differentiation. The models can further be used to design therapies to ameliorate bone destruction in the Rheumatoid Arthritis affected joints. 


\section{Effects of Rheumatoid Arthritis associated transcriptional}

\section{2 changes on osteoclast differentiation network in the}

\section{3 synovium}

4 Shilpa Harshan ${ }^{1,+}$, Poulami Dey ${ }^{1,2,+}$, Srivatsan Raghunathan ${ }^{1 *}$

$5{ }^{1}$ Institute of Bioinformatics and Applied Biotechnology (IBAB), Biotech Park, Electronic City

6 Phase I, Bengaluru 560 100, Karnataka, India.

$7 \quad 2$ Manipal Academy of Higher Education, Manipal, 576104, Karnataka, India.

$8 *$ srivatsan@ibab.ac.in

$9+$ These authors contributed equally to this work 


\section{Abstract}

\section{Background}

12 Osteoclast differentiation in the inflamed synovium of Rheumatoid Arthritis affected joints leads

13 to the formation of bone lesions. Reconstruction and analysis of protein interaction networks

14 underlying specific disease phenotypes are essential for designing therapeutic interventions. In

15 this study we have created a network that captures signal flow leading to osteoclast

16 differentiation. Based on transcriptome analysis, we have indicated the potential mechanisms

17 responsible for the phenotype in the Rheumatoid Arthritis affected synovium.

\section{Method}

19 We collected information on gene expression, pathways and protein interactions related to

20 Rheumatoid Arthritis from literature and databases namely Gene Expression Omnibus, KEGG

21 pathway and STRING. Based on these information, we created a network for the differentiation

22 of osteoclasts. We identified the differentially regulated network genes and reported the

23 signaling that are responsible for the process in the Rheumatoid Arthritis affected synovium.

\section{Result}

25 Our network reveals the mechanisms underlying the activation of the Neutrophil Cytosolic

26 Factor complex in connection to osteoclastogenesis in Rheumatoid Arthritis. Additionally, the

27 study reports the predominance of the canonical pathway of NF- $\kappa$ B activation in the diseased

28 synovium. The network also confirms that the upregulation of $\mathrm{T}$ cell receptor signaling and

29 downregulation of TGF $\beta$ signaling pathway favour osteoclastogenesis in Rheumatoid Arthritis. 
30 To the best of our knowledge, this is the first comprehensive protein-protein interaction network

31 describing Rheumatoid Arthritis driven osteoclastogenesis in the synovium.

\section{Discussion}

33 This study provides information that can be used to build models of the signal flow involved in

34 the process of osteoclast differentiation. The models can further be used to design therapies to

35 ameliorate bone destruction in the Rheumatoid Arthritis affected joints.

\section{Introduction}

37 Rheumatoid arthritis (RA) is a systemic autoimmune disease that primarily affects synovial joints. The disease is characterised by chronic inflammation in the joints, leading to synovial hyperplasia (pannus formation), destruction of the cartilage and erosion of the underlying bone.

RA is a complex disease involving several molecular pathways across various cell types and tissues. Thus in order to elucidate the underlying cause of a particular phenotype associated to the disease, identification of the network consisting of differentially expressed genes (DEG) in the interacting pathways is essential. Studies have used pathway analysis to identify affected pathways from lists of DEGs (Hao et al., 2017; Wang et al., 2017; Lee et al., 2011; Wu et al., 2010). The lists have also been used to create networks that are related to specific diseases or conditions. Earlier work using RA samples has focused on generating networks of the genes

47 showing differential regulation (Hao et al., 2017; Wang et al., 2017) or the most enriched gene ontology (GO) ("Expansion of the Gene Ontology knowledgebase and resources.," 2017) category in the DEG lists (Lee et al., 2011). A comprehensive network describing molecular interactions across various RA affected tissues was created using publicly available microarray data by $\mathrm{Wu}$ et al (Wu et al., 2010). Other groups have created gene regulatory networks (GRN) 
52 using in vitro data from cultured fibroblasts and macrophages (Kupfer et al., 2014; You et al.,

53 2014). Kupfer et al (Kupfer et al., 2014) used time series data generated from RA synovial

54 fibroblasts subjected to external stimulation to create a GRN. They simulated the network to

55 analyse the behaviour of genes involved in RA pathogenesis, in response to stimulation by RA

56 associated cytokines and growth factors. You et al (You et al., 2014) created a GRN and

57 identified the critical interactions responsible for synovial fibroblast invasiveness in RA

58 synovium. The creation of a detailed protein-protein interaction (PPI) network describing the

59 connections between various pathways involved in any specific RA process, at the level of the

60 synovial tissue, is yet to be attempted. In this study, using the publicly available gene expression

61 data for RA synovial tissue and protein interactions and pathway databases, we created and

62 analysed a detailed phenotype-specific PPI network. We used differentially regulated genes to

63 identify the altered pathways in the affected synovium. We identified the pathway of osteoclast

64 differentiation as a phenotype connected to many of the altered pathways in the RA synovium. It

65 is established that the RA synovium harbors osteoclasts, the cells responsible for bone

66 degradation in the affected joints (Schett, 2007). Therefore, a network of proteins participating in

67 the interacting pathways underlying the RA associated process of osteoclast differentiation in the

68 synovium was created for the first time. We report the upregulated signaling routes that drive

69 osteoclastogenesis via the generation of reactive oxygen species (ROS) by Neutrophil Cytosolic

70 Factor (NCF) complex in the RA synovium. We demonstrate the contribution of elevated $\mathrm{T}$ cell

71 receptor signaling in facilitating osteoclast differentiation in the affected tissue. In addition, we

72 describe the importance of the canonical pathway of NF- $\kappa \mathrm{B}$ activation and the TGF $\beta$ pathway in

73 connection to the process. Finally, the network reports all the possible routes by which the

74 inflamed synovium promotes the differentiation of osteoclasts. 


\section{Materials and Methods}

This study involved two major steps: selection of a phenotype exhibited by the RA synovium, and construction and analysis of a PPI network for the selected phenotype. Figure 1 shows the detailed workflow that was followed. Each step is described in detail in this section. The databases used in this study are summarized in Table 1.

\section{Identification of DEGs using microarray data analysis}

The DEGs were obtained by re-analysing the publicly available microarray datasets in Gene Expression Omnibus (GEO) (Edgar, Domrachev \& Lash, 2002) database. The repository was searched for the data generated from synovial tissue in RA patients and healthy controls. The results were further narrowed down by considering only the data from Affymetrix platforms with at least four RA and four control samples. Datasets selected for the study are mentioned in Table 2.

Of the seven datasets, information regarding treatments received by the patients was not available for GSE77298 (Broeren et al., 2016) and GSE7307. Earlier, it was established that the differential regulation of the genes in these datasets was not under the influence of drug therapy (Dey, Panga \& Raghunathan, 2016). The clinical information for the RA patients was available for the datasets GSE1919 (Ungethuem et al., 2010), GSE12021 (U133A) (Huber et al., 2008), GSE12021 (U133B) (Huber et al., 2008), GSE55235 (Woetzel et al., 2014) and GSE55457 (Woetzel et al., 2014). The erythrocyte sedimentation rate (ESR) and the concentration of Creactive protein (CRP) reported for these datasets were higher than $40 \mathrm{~mm}^{\text {hour }}{ }^{-1}$ and $21 \mathrm{mg}$ litre-

${ }^{1}$ respectively. These values indicated active inflammation in the synovium of the RA patients 
96 (Wetteland et al., 1996 ; Otterness, 1994). For the datasets, GSE77298 and GSE 7307, the values

97 for these parameters were not available.

98 Raw data from the seven datasets along with their metadata was downloaded using the $\mathrm{R}$ 99 libraries GEOquery (Davis \& Meltzer, 2007) and GEOmetadb (Zhu et al., 2008). The data was 100 analysed using the affy (Gautier et al., 2004) and simpleaffy (Wilson \& Miller, 2005) libraries in 101 the Bioconductor package in R (R Core Team, 2017).

102 In this analysis, two algorithms, Robust Multiarray Average (RMA) and Microarray Suite 5.0 103 (MAS5) were used for the data normalization. The choice of data normalization algorithms affect 104 the final selection of the DEGs (Pepper et al., 2007). In order to reduce the algorithm specific 105 effects, both RMA and MAS5 were used in this study. In the case of MAS5, probesets having at 106 least one present call ("P") in control as well as treatment samples were considered. Probesets 107 were annotated with Entrez IDs using the Bioconductor as well as DAVID gene-ID conversion 108 tool (Huang, Sherman \& Lempicki, 2009b; Huang, Sherman \& Lempicki, 2009a). Welch t test was applied to calculate the significance for differential expression between the RA and the control samples. As per the recommendations by Huang et al (Huang, Sherman \& Lempicki, 2009a), in our study a gene with a linear fold change of 2 (for up and downregulation) and a $p$ value $<=0.05$ was considered to be differentially expressed. A final list of DEGs, from the seven datasets, was obtained using the selection rules as described below:

114 A. In a dataset, a gene is considered to be upregulated if:

115 i. It is upregulated in both RMA and MAS5 $[+,+]$ Or,

117 ii. It is upregulated in one of the algorithm and not differentially expressed in the other 118

$$
[+, 0] \text { or }[0,+] \text {. }
$$


B. Across the datasets, the gene is upregulated if:

120 i. It is $[+,+]$ in at least one of the seven datasets and no downregulation in any of the

ii. It is $[+, 0]$, in at least one dataset and $[0,+]$ in at least one of the remaining datasets while there is no downregulation in any one of them

The same procedure was repeated for the downregulated genes.

126 When the selection criteria was made more stringent by demanding the selection of a gene in at

127 least two datasets, the number of selected genes reduced by almost 50 percent as shown in Fig. 2.

Since the aim of the study was to identify all the important signaling associated with the RAassociated process we decided to proceed with the selection criteria of presence in at least one dataset.

Finally, we prepared a list of up and downregulated genes which we named as "common-up" and "common-down" respectively.

\section{Pathway Analysis:}

The common-up and common-down gene lists were separately examined for the enrichment of pathways listed in the Kyoto Encyclopedia Of Genes And Genomes (KEGG) database (Kanehisa et al., 2017) using Database for Annotation, Visualization and Integrated Discovery (DAVID).

137 For the enrichment analysis, we created a custom background by combining the total probesets 138 present on all four microarray platforms and annotating them with Entrez IDs using the DAVID gene ID conversion tool. The pathways which were significantly over-represented in the 140 common-up or common-down gene lists with an EASE score $<=0.05$ and fold enrichment $>=$ 
1411.5 were considered to be affected in RA (Huang, Sherman \& Lempicki, 2009a). EASE score is 142 a modified one-tailed Fisher exact probability used in enrichment analysis (Hosack et al., 2003).

143 The pathways were grouped according to their KEGG categories. Those belonging to the 144 categories "human diseases", "metabolism" or the ones lacking protein-protein interactions were 145 not considered further. The category "human diseases" contains pathways that represent specific 146 disease conditions. These were excluded because they do not reflect the protein-protein 147 interaction in healthy conditions. "Metabolism" contains pathways that describe interconversions 148 of metabolites. Since this study focused on PPI involved in the RA affected synovium, we did 149 not consider the metabolic pathways. The remaining pathways were categorized based on their 150 functional specificity. The pathways which result in a specific function like platelet activation 151 were tagged as process pathways, whereas the pathways describing more general signaling 152 events like the activation of multiple transcription factors through $\mathrm{T}$ cell receptor signaling, were 153 considered as signaling pathways.

154 The list of genes present in each selected pathway was downloaded from KEGG using the 155 KEGGREST (Tenenbaum, 2017) package in R. For each one of the selected pathway, the list of 156 genes that were common between the pathway and the microarray platforms was created. We 157 name this as "S-list". By the pairwise intersection of the S-list of each process pathway with 158 every one of the non-disease pathway, we obtained the DEGs shared between the pairs of 159 process and non-disease pathways. The number of DEGs shared by each pair was examined. The 160 pairs of pathways sharing at least five upregulated or five downregulated genes were retained for 161 our study. Figure 3 shows the number of up or downregulated genes common to the pair of 162 pathways. It is evident from this figure that the above mentioned criterion did not result in a bias 163 towards pairs of larger pathways. 


\section{Construction of network:}

165 We constructed a PPI network for the osteoclast differentiation. The osteoclast differentiation 166 pathway (ODP) proteins, obtained from KEGG were defined as a set of core proteins. Interactors 167 of the core proteins (first-shell interactors) were extracted from the STRING database (version 168 10) (Szklarczyk et al., 2015). The protein list was restricted by considering only experimentally 169 validated interactions with a score of $>=0.9$. This score on a scale of 0 to 1 represents the 170 confidence of experimental validation with maximum confidence being 1 . We obtained the

171 directions for these interactions from the literature references used in STRING, when available, 172 or with a separate literature search in Pubmed. The complete network was built in Cytoscape 173 (Shannon et al., 2003) using all the obtained interactions. The proteins corresponding to the 174 DEGs in RA synovium obtained from the microarray data analysis were indicated in this 175 network.

\section{Analysis of the network:}

177 The network was a mixed network consisting of the undirected protein binding edges and the 178 directed edges of activation, inhibition or the post-translational modification (PTM). The nodes 179 are labelled using the official gene symbols corresponding to the proteins used to create the network. The interactions involved undirected protein-protein interactions or directional PTM like phosphorylation, methylation, acetylation, ubiquitination etc. We included activation or inhibition as an interaction whenever the reference mentioned that the target protein is activated or inhibited as a result of the interaction. We created a version of this directed network without UBC and its edges. We named this version as "directed ODP network". 
185 We conducted GO enrichment analysis on the directed ODP network proteins using the GO 186 molecular function (GOMF) and GO biological process (GOBP) terms. Terms with an EASE 187 score $<=0.05$ and fold enrichment $>=1.5$ were considered as enriched. We combined 23 enriched 188 GOMF terms to identify the proteins that bind to DNA. In the case of the GOBP terms, we selected the enriched signaling terms that contained differentially regulated genes for $\mathrm{T}$ cell receptor signaling, $\mathrm{B}$ cell receptor signaling and $\mathrm{FC}-\varepsilon$ receptor signaling. For NF- $\kappa \mathrm{B}$ signaling, TLR signaling and TGF $\beta$ signaling pathways we combined six, nine and three enriched terms respectively and examined their differential regulation. Using the selected enriched signaling terms, we extracted subnetworks corresponding to each signaling pathway from the directed

ODP network. All the subnetworks demonstrate the flow of information from the first-shell interactor proteins to the core proteins of the ODP network. The details of the GOMF and GOBP signaling terms enriched in the analysis is provided in the Tables S1 and S2 respectively.

197

The database DrugBank (Wishart et al., 2018) was explored to locate the target proteins of drugs that are commonly used in the treatment of RA. We used the information to pinpoint the network proteins which are targets of the RA drugs. The details regarding the drugs and their targets are submitted in Table S3.

We converted all the edges of the directed ODP network to single undirected protein binding edges to create an "undirected ODP network". We analysed this network using the Cytoscape plugin NetworkAnalyzer (Assenov et al., 2008). We used the plugin MCODE v1.5.1. (Bader \& Hogue, 2003) to identify the clusters in the network.

\section{Results}

\section{Differentially expressed genes in RA synovium}


207 We analysed seven Affymetrix microarray datasets from five different platforms. Out of 21,246

208 Entrez annotated genes measured, 1018 upregulated and 893 downregulated genes were

209 identified in the RA synovium compared to the healthy controls. The differentially regulated

210 genes are submitted in Table S4. Only three genes STAT1, IL7R and IGKC were upregulated in

211 all seven datasets. Interestingly, three AP1 proteins FOSB, JUN and JUNB were downregulated.

212 Table 3 shows the datasets in which the genes were downregulated.

\section{Diverse pathways are involved in the disease processes affecting the RA synovium}

214 Using the DEGs from the microarray analysis as the input, we found that 52 KEGG pathways

215 were enriched in the upregulated gene list, and 29 in the downregulated gene list. The EASE

216 scores of the selected pathways were much less that the cut-off of 0.05 . The enrichment analysis

217 when performed with the combined DEG list (1018 up genes +893 down genes) resulted in only

21855 pathways. Among these, only two pathways were newly obtained when compared to the

219 previous list of 52 upregulated and 29 downregulated pathways. As the combined analysis

220 proved less informative, the 52 up and 29 downregulated pathways were considered for the

221 study. Three pathways, namely, Extra cellular matrix (ECM)-receptor interaction, Focal adhesion

222 and Proteoglycans in cancer occurred in both the up and downregulated pathway lists because

223 each pathway had a significant number of up and downregulated genes. The KEGG category-

224 wise distributions of the enriched pathways are shown in Fig. 4 and Fig. 5 and the detailed

225 results of the pathway analysis are given in the Table S5 and S6. 26 of the upregulated pathways

226 and four of the downregulated pathways belonged to the KEGG category "human diseases".

227 Among the upregulated non-disease pathways, the category "immune system" had the highest

228 number of enriched pathways. Most of the immune receptor signaling pathways in this category

229 were upregulated. Among the other signaling pathways, NF- $\kappa \mathrm{B}$ and JAK-STAT signaling 
230 pathways were upregulated in our analysis. All the signaling pathways which belong to the

231 KEGG categories, "immune system" and "signal transduction" that were enriched in the

232 upregulated gene list are shown in Table 4.

233 Specialized cells called osteoclasts which facilitate bone resorption are also present in the 234 invading pannus of the RA joints (Gravallese et al., 1998; Jung et al., 2014; Nevius, Gomes \& 235 Pereira, 2016). All the five microarray datasets which provided information on the disease state, GSE1919, GSE12021 (U133A), GSE12021 (U133B), GSE55235 and GSE55457, used tissue

237 from patients with more than ten years of disease. Patients from the other dataset GSE77298, 238 were at the end stage of the disease. Since osteoclast differentiation is reported in severely 239 inflamed RA synovium, the process is likely to be detected in the synovial tissue used for the 240 datasets. It is noteworthy that our analysis identified the pathway osteoclast differentiation as one 241 of the enriched pathways with a fold enrichment of 3.11 (EASE score of $2.41 \mathrm{e}^{-8}$ ) in the RA 242 synovium. In addition, our analysis detected the upregulation of two well-known osteoclast 243 markers Cathepsin K (CTSK) and tartarate resistant acid phosphatase (ACP5) in the synovium.

244 The category highly represented in the list of downregulated pathways was "signal transduction".

245 All the signal transduction pathways enriched in the downregulated gene list are given in Table

246 5. In contrast to the upregulated pathways, the downregulated pathways included several 247 metabolic pathways such as fatty acid degradation, fatty acid elongation etc. Some endocrine 248 system pathways like regulation of lipolysis in adipocytes, insulin signaling pathway, which are 249 closely related to metabolic regulation were also listed among the downregulated pathways.

250 RA affected signaling pathways interact to orchestrate osteoclast differentiation in the 251 synovium 
252 We categorised the 26 upregulated and 25 downregulated non-disease pathways based on their

253 functional specificity. In this analysis we identified 12 process pathways and 19 signaling

254 pathways among the differentially regulated pathways. This list of 31 pathways includes the

255 process pathway focal adhesion which was differentially regulated in both directions. While four

256 and ten process and signaling pathways respectively were downregulated, nine process and

257 signaling pathways each were upregulated. The detailed information about the number of

258 upregulated, downregulated and total genes in each of the selected pathway is submitted as Table

259 S7 and S8.

260 We examined the overlap of the process pathways with all the non-disease pathways based on

261 the shared number of DEGs. The overlapping pathways are represented as a pathway interaction

262 network in Fig. 6. Several of the signaling pathways share DEGs with the process pathways

263 indicating that the process is influenced by these signaling pathways. The details of the DEGs

264 shared by each pathway pair is presented in the Table S9.

265 Figure 7 is a graphical representation of the number of genes shared between the Osteoclast

266 differentiation pathway and other non-disease pathways. Signaling pathways, represented by

267 light blue bars, constitute eight out of the 13 non-disease pathways that interact with osteoclast

268 differentiation. All the pathways sharing genes with osteoclast differentiation pathways are

269 upregulated pathways. Similar graphs were created for all upregulated process pathways and are

270 available in the supplementary figures: Fig. S1 - Fig. S7. Figure 8 shows the overlap analysis for

271 the downregulated signaling pathways.

272 Among the downregulated process pathways shown in Fig. 8, vascular smooth muscle

273 contraction interacted with platelet activation and cGMP-PKG signaling pathway, via

274 downregulated genes in the RA synovium. Regulation of lipolysis in adipocytes interacted only 
275 with down signaling pathways through downregulated genes. Finally, the pathway adherens

276 junction did not overlap with any other pathways.

277 Our study revealed that the processes of natural killer cell mediated cytotoxicity as well as

278 osteoclast differentiation involved a network of several interacting pathways in the RA

279 synovium. However, osteoclast differentiation was influenced by the highest number of signaling

280 pathways. This indicates that the differentiation of osteoclasts in the RA synovium is coordinated

281 by several signaling pathways. In order to understand the collective effect of these signaling

282 pathways on the osteoclast differentiation, we created a detailed PPI network for the process in

283 the RA synovium. Among all the interactions obtained from the STRING database, we used only

284 the experimentally validated ones published in literature, for the creation of the network. In this

285 network, we indicated the differentially regulated genes from the microarray analysis to show the

286 possible ways by which the altered signaling promotes osteoclastogenesis in RA synovium.

287 A comprehensive PPI network for the differentiation of osteoclasts in RA synovium

288 The PPI network, created in our study, had 433 proteins and 1790 interactions. The network

289 consisted of three connected components. The two smaller connected components were the

290 interactions between CD47 and SIRPA, and IL1A and S100A13.

291 The protein Ubiquitin which has the highest number of interactions in the network was found to

292 interact with 175 network proteins. This is expected, as ubiquitination is a very common PTM

293 that marks the proteins for proteasomal degradation. In our network, ubiquitination was

294 represented as interaction of a protein with ubiquitin as well as with ubiquitin ligases. We

295 removed ubiquitin from our network since most of the edges of ubiquitin and those of the

296 ubiquitin ligases were redundant. The resulting network had 432 proteins and 1595 interactions. 
297 In this network, in addition to the two small connected components, four proteins, PPP3R1, 298 PPP3CA, PPIA and RCAN1 were disconnected from the main network and formed a new 299 connected component. The network now had four components: CD47-SIRPA, IL1A-S100A13, 300 PPP3R1-PPP3CA-PPIA-RCAN1, and one large component.

301 We removed the three smaller connected components from the main network. The large 302 connected component, consisting of 424 protein nodes and 1589 interactions, was used for 303 further analysis. Henceforth, we refer to this as directed ODP network. The directed ODP 304 network contains 82 core proteins belonging to the KEGG osteoclast differentiation pathway.

305 The portion of the directed ODP network containing the 82 core proteins and their 152 306 connections is termed as the "core network" (directed). The rest of the network consisting of the 307 first shell interactors and their edges is the "shell network" (directed). The core network contains proteins which are directly involved in the osteoclast differentiation. The shell network represents the protein milieu in the RA synovium facilitating the osteoclast differentiation. The complete directed ODP network is provided as a supplementary file S1. A second supplementary file S2 contains the information about the core and shell proteins of the ODP network.

\section{The DNA-binding proteins of the directed ODP network}

313 In a PPI network, the terminal responders of the signals are the DNA-binding proteins such as a

314 transcription factors $(\mathrm{TF})$, coactivator etc. or the proteins that generate non-protein signaling 315 molecules like secondary messengers. Using the enriched terms in the category GOMF, we classified 82 of the 424 nodes as DNA-binding proteins (Fig. S8). 18 DNA- binding proteins which include STAT, NF- $\kappa$ B and AP1 TF belong to the core network. Along with the differential expression of STAT1, JUN, JUNB and FOSB, the STAT protein STAT2 was upregulated in this 319 study. 
320 In addition to STAT and AP1 proteins, the other DNA binding core protein PPARG was

321 observed to be downregulated which is in agreement with the results of Li et al (Li et al., 2017).

322 The attachment of the shell network resulted in the inclusion of nine differentially regulated

323 DNA-binding proteins in the directed ODP network. The possible roles of these proteins in

324 osteoclastogenesis are described in context of their GOBP terms.

\section{The signaling pathways of the directed ODP network}

326 GOBP over-representation analysis of the directed ODP network proteins identified several

327 immune signaling terms. These terms included five out of the eight upregulated KEGG signaling 328 pathways which were found to interact with the osteoclast differentiation (Fig. 7). These

329 pathways are: T cell receptor signaling pathway, B cell receptor signaling pathway, Fc- $\varepsilon$ receptor

330 signaling pathway, NF- $\mathrm{B}$ signaling pathway and Toll-like receptor (TLR) signaling pathway.

331 Among these, $\mathrm{T}$ cell receptor signaling pathway had the most number of DEGs, with 14 up and 332 one downregulated nodes. The proteins belonging to the $\mathrm{T}$ cell receptor signaling term were 333 extracted as a subnetwork (Fig. S9). In this subnetwork, the T cell surface molecules CD3E and 334 CD28 were upregulated whereas CD247 did not show differential regulation. The downstream 335 signaling molecules ZAP70, LCK, ITK, CSK, LAT, LCP2, FYB, PAG1, PIK3CD, MAPK1, 336 PLCG2 and INPP5D were upregulated. Among them, PIK3CD, MAPK1, LCK, LCP2 and 337 PLCG2 are the core network proteins.

338 The B cell receptor signaling pathway (Fig. S10) term shared six proteins with the core network.

339 Five of these core proteins were upregulated. In addition, ZAP70, LYN and PRKCB, which are 340 part of the shell network, were found to be upregulated. 
341 The Fc- $\varepsilon$ receptor signaling pathway (Fig. S11) showed the MAP Kinase, NF- $\kappa$, Rac signaling

342 components. The term showed nine upregulated genes which included the receptor FCER1G.

343 Six GOBP terms were combined to extract 75 proteins of the NF- $\kappa$ B signaling pathway from the 344 directed ODP network (Fig. S12). This NF- $\kappa$ B subnetwork contained five receptors including 345 one core protein (TNFRSF1A). Out of the 11 DEGs in the subnetwork, TNFSF11 (RANKL) and 346 STAT1 were the core proteins. REL, a component of NF- $\kappa \mathrm{B}$ transcription factor dimers was 347 upregulated. The osteoclast differentiation and activation factor, RANKL, an activator of NF- $\kappa B$ 348 pathway was highly upregulated with a $\log 2$ fold change of 3.32 . It is known that REL 349 participates in the canonical NF- $\mathrm{B}$ signaling (Shih et al., 2011). Of the many possible signaling 350 routes leading to REL, we observed DEGs in the following pathways: TCR-PRKCQ-CARD11351 BCL10; IL1R1-MyD88-IRAK4; TNFSF11 (RANKL)-TRAF6-IKK; CD27-TRAF2-IKK. We

352 have extracted all these routes and created a subnetwork for activation of REL in the RA 353 synovium (Fig. 9).

354 We combined nine over-represented GOBP terms to extract the TLR signaling pathway proteins 355 (Fig. S13). The extracted subnetwork featured the signaling from the receptors TLR3 and TLR4 356 to the IאB kinase complex (IKK). Although the pathway is upregulated in the RA synovium, the 357 TLR receptors in the ODP network did not show any differential regulation.

358 Interestingly, the directed ODP network demonstrated a downregulation of all the DEGs 359 participating in the TGF $\beta$ signaling pathway. The TGF $\beta$ subnetwork (Fig. S14) showed the 360 presence of the ligands TGFB1, TGFB2 and TGFB3 and the receptors TGFBR1, TGFBR2 and 361 TGFBR3. Among the downstream SMADs, SMAD3 was downregulated.

\section{Protein clusters in the directed ODP network}


363 The analysis done using the MCODE application of the Cytoscape tool revealed 19 clusters

364 which may indicate functional protein complexes. The details of these 19 clusters are submitted

365 as Table S10. Among them, 12 clusters included a mixture of core and shell proteins. In three of

366 the clusters (Cluster2, Cluster 4 and Cluster 10), the core proteins were differentially regulated.

367 Cluster 2 comprised of three core proteins and six shell proteins. The cluster had two DEGs

368 which were DNA-binding proteins STAT1 and PPARG. Cluster 4 was a TGF $\beta$ cluster and 369 cluster 10 was an NCF cluster. The TGF $\beta$ cluster had two downregulated proteins, of which

370 SMAD3 was a shell protein. The NCF cluster had four core proteins, of which NCF2, NCF4 and

371 CYBA were upregulated. The upregulated shell protein in the NCF cluster was NCF1.

\section{Discussion}

373 This study is aimed at understanding the mechanisms involved in a specific RA-related 374 phenotype. We have used a large number of microarray studies and relaxed inclusion criteria for

375 differential expression across datasets, to obtain relatively large number of DEGs that are likely

376 to be involved in RA. We have combined this gene expression data with pathway analysis and

377 identified various process pathways and several signaling pathways to be affected by RA. In

378 systemic diseases like RA, pathways responsible for a particular phenotype operate in an 379 environment consisting of various other disrupted pathways. Thus it becomes important to 380 understand the effect of this environment on the pathway immediately responsible for the 381 phenotype. We attempted to achieve this by overlapping the various process pathways with the 382 enriched signaling pathways in the synovium. Interestingly, the process pathway osteoclast 383 differentiation overlapped with several of the enriched signaling pathways. In order to 384 understand the signaling involved in osteoclast differentiation in the RA synovium, for the first 
385 time, we created a detailed PPI network responsible for the phenomenon. Each interaction in this

386 network was manually verified from literature enabling the inclusion of directions of the

387 interactions and specific post translational modifications whenever such information was

388 available. While creating the network using all the possible interactions available in STRING,

389 we found that some proteins in the repository have more number of interactions reported than the

390 others. We acknowledge that this might have led to a bias in the directed ODP network. The

391 network lacks the important non-protein molecules involved in triggering the ectopic

392 differentiation of osteoclasts in the inflamed synovium. In addition, gene expression regulation

393 resulting from activation or repression of transcription factors was not depicted in the network.

394 Since the RA specific data used in this network was only gene expression data, information on

395 the activation state of specific proteins that are known to be involved in the disease, e.g., 396 phosphorylation state of STAT1 was missing. Though the network lacks these information, it is

397 the most comprehensive and informative PPI network till date describing the process of 398 osteoclast differentiation.

399 The differentially regulated genes in the RA synovium

400 In order to identify the DEGs in the RA synovium, seven microarray datasets generated by five 401 different studies were used. Among the seven datasets, the RA patients belonging to the datasets 402 GSE1919, GSE12021 (U133A), GSE12021 (U133B), GS55235 and GSE55457 had similar high

403 values for the inflammatory markers, ESR and CRP. Additionally, the tissue used in GSE77298 404 were described as end stage RA synovial biopsies. Therefore, we surmise that the RA tissues 405 were highly inflamed. However, we observed that few genes were differentially expressed across 406 most of the datasets (Fig. 2). Since the level of inflammation in RA tissues were comparable, we 407 attribute this lack of concordance between the datasets to the heterogeneity of the disease. 


\section{The enriched pathways in the RA synovium}

409 KEGG pathway enrichment analysis of the upregulated genes (common-up) resulted in 26

410 upregulated disease pathways. As expected, Rheumatoid arthritis was one of these disease

411 pathways. Staphylococcus aureus infection and Tuberculosis, the two upregulated infectious

412 disease pathways in the results of the pathway enrichment analysis are known to be associated

413 with RA (Sams et al., 2015; Jeong et al., 2017). The upregulated infectious disease pathways

414 share several genes with immune system pathways. Differential regulation of the immune

415 pathways is expected in RA since it is an immune disorder. Therefore, the upregulation of the

416 immune genes explains the enrichment of the infectious disease pathways in the up pathway list.

417 Several pathways belonging to the category "immune system" were enriched in the common-up

418 genes. The enrichment of these immune pathways is likely as infiltration of activated immune

419 cells has been observed in the RA synovium (McInnes \& Schett, 2011). In addition, the resident

420 cells of the inflamed pannus exhibit activation of several immune signaling pathways (McInnes

$421 \&$ Schett, 2007). Among the pathways from Table 4, the Fc- $\varepsilon$ RI signaling pathway shows an

422 upregulation of the IgE receptor Fc- $\varepsilon$ RI. Elevated presence of $\operatorname{IgE}$ and activated mast cells have

423 been detected in the RA synovium (Gruber, Ballan \& Gorevic, 1988; Tetlow \& Woolley, 1995).

424 It has been demonstrated by in vitro experiments that the RA synovial mast cells express Fc- $\varepsilon$ RI 425 and can be activated via the Fc- $\varepsilon$ RI signaling pathway (Lee et al., 2013). However, the 426 contribution of the pathway to the pathological alteration of synovial tissue function needs to be 427 addressed in future studies.

428 Among the enriched downregulated pathways, seven belong to the category "signal 429 transduction" (Table 5). The AMPK signaling pathway which is known for its anti-inflammatory 430 effect shows downregulation in our analysis (Speirs et al., 2018). The downregulation of the 
431 FOXO signaling pathway is also observed in this study. This reflects the results of the earlier

432 studies which have shown downregulation and inactivation of the FOXO transcription factors in

433 the RA affected synovium (Ludikhuize et al., 2007; Grabiec et al., 2015). Additionally, the

434 FOXO proteins are inhibited by NF- $\mathrm{BB}$ signaling, and activated by AMPK as shown in the

435 FOXO signaling pathway listed in KEGG pathway database. The pathway enrichment results

436 from our analysis show upregulation in $\mathrm{NF}-\kappa \mathrm{B}$ signaling and downregulation in AMPK

437 signaling, which explains the downregulation of FOXO signaling. Further, the cGMP-PKG

438 signaling is known to be essential for the vascular smooth muscle response to the inflammatory

439 cytokines (Browner, Sellak \& Lincoln, 2004). The downregulation of genes in this pathway

440 needs to be studied in detail to analyse the effects of RA synovial inflammation on the blood

441 vessels in the affected tissue. The cAMP signaling pathway is known to facilitate regulatory $\mathrm{T}$

442 cell function and T cell anergy (Raker, Becker \& Steinbrink, 2016). The downregulation in this

443 pathway might indicate the pro-inflammatory nature of the infiltrating $\mathrm{T}$ cells in the synovium. It

444 is difficult to explain the importance of downregulation in the Wnt signaling pathway and the

445 MAPK signaling pathway in the RA synovium. Wnt signaling, which is required for repair of

446 bone erosions, is suppressed in mouse models of inflammatory arthritis (Lories, Corr \& Lane,

447 2013). However, Wnt signaling has also been linked to proinflammatory cytokine production in

448 the affected synovium (Miao et al., 2013). In our study, the KEGG Wnt signaling pathway is

449 enriched in downregulated genes. Among the downregulated genes, two are Wnt receptors FZD4

450 and LRP6, whereas three are the Wnt antagonists SFRP1, SFRP2 and SFRP. Thus no

451 conclusions can be made about the role of Wnt signaling pathway from its presence in the list of

452 downregulated pathways. Similarly, no clear picture can be drawn about the role of MAPK

453 signaling pathway in the RA synovium. This is because the KEGG MAPK signaling pathway is 
454 very large, with 252 genes and several genes are grouped together under terms like RTK

455 (receptor tyrosine kinase) and GF (growth factor), making the pathway extremely general.

\section{Construction of the directed ODP network}

457 Three small connected components were removed while creating the directed ODP network. One 458 of the components contained the proteins PPP3R1 and PPP3CA which are the subunits of 459 calcineurin, an important regulator of osteoclast differentiation. The immunosuppressant drug 460 cyclosporin used in the treatment of RA acts as an inhibitor of calcineurin by forming a ternary 461 complex with PPIA and calcineurin (Wang \& Heitman, 2005). The remaining protein in the 462 connected component, RCAN1 is an inhibitor of calcineurin. Both in the KEGG pathway 463 database and in literature, these proteins are described as participating in the RANKL signaling 464 pathway which regulates the differentiation of osteoclasts. Calcineurin participates in the 465 RANKL signaling pathway downstream of the non-protein components inositol triphosphate and 466 calcium ions. Since our network is based on protein-protein interactions, it failed to capture the 467 connection of calcineurin and its adjacent proteins to the large connected component, in spite of 468 showing the connections of other RANKL pathway proteins.

\section{Analysis of the directed ODP network}

470 The directed ODP network was analysed to examine three main aspects. Firstly, the proteins

471 binding to DNA were explored because they are involved in regulating gene expression.

472 Secondly, the proteins involved in signal transduction were studied for their role in facilitating

473 the process of osteoclast differentiation in the RA affected synovium. Finally, the clusters of 474 highly interconnected proteins were identified in the network. Several proteins function as part of 475 protein complexes. The protein clusters we identified may represent the protein complexes. We 476 also examined the differential expression of the proteins in the clusters. Protein clusters with 
477 differentially regulated proteins may represent complexes actively involved in the

478 osteoclastogenesis in RA synovium.

479 DNA binding proteins in the directed ODP network

480

481

482

483

484

485

486

487

488

489

490

491

492

493

494

495

496

497

498

499

Among the DNA-binding proteins in the directed ODP network, the downregulation of the AP1 proteins JUN and JUNB is in contrast to the earlier studies which reported their upregulation in RA synovium (Kinne et al., 1995). As shown in Table 3, the AP1 downregulation was observed in five of the seven datasets, with the three proteins FOSB, JUN and JUNB being downregulated in three out of the seven datasets. The presence of consistent downregulation in the datasets from different studies shows that the downregulation of these proteins is not due to dataset specific factors. As mentioned earlier, four of the five datasets showing downregulation had patients with similar clinical characteristics. This may suggest a connection between the stage of the disease and the downregulation of the AP1 proteins. Further studies are required to explain the downregulation of these AP1 proteins in the synovium of a subset of RA patients.

According to previous reports, another AP1 protein FOS is upregulated in the RA synovium (Dooley et al., 1996). However, our analysis does not show any differential regulation of FOS. FOS is an indispensable transcription factor for osteoclast differentiation (Grigoriadis et al., 1994). In the ODP network, the upregulation of MAPK1 and RPS6KA1 presents a possible mechanism for FOS activation. In addition, our network reveals the activation of FOS by the upregulated TF STAT1. Along with STAT1, the TF STAT2, the kinase JAK2 and the receptor IFNAR2 were upregulated in the IFN pathway of the ODP network. TNFSF11 (RANKL) induces expression of IFN $\beta$ which serves as a feedback inhibitor of osteoclastogenesis via STAT1 (Xiong et al., 2016). The upregulation of the IFN $\beta$ receptor, IFNAR2 and the TF STAT1 may indicate that the feedback inhibition is functional in the RA synovium. 


\section{Signaling pathways in the directed ODP network}

501 The examination of the enriched GOBP terms of the network showed an involvement of $\mathrm{T}$ cell

502 receptor signaling pathway, B cell receptor signaling pathway, Fc- $\varepsilon$ receptor signaling pathway 503 and NF- $\mathrm{B}$ signaling pathway in the differentiation of osteoclasts in the RA synovium. Figure 9

504 depicts the signaling routes that lead to activation of REL in the RA synovium. The figure shows 505 activation of REL by PKC. The network shows T cell receptor mediated activation of PRKCQ 506 and its subsequent activation of CARD11. Based on earlier studies (Szamel, Bartels \& Resch, 507 1993; Sommer et al., 2005), we speculate that another isoform of PKC, PRKCB is also involved 508 in the activation of CARD11 in the affected synovium. It is known that the activated CARD11 509 via the formation of a trimeric complex with BCL10 and MALT1 activates the IKK complex

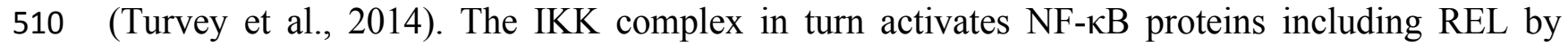
511 removing their inhibition by NFKBIA and NFKBIB. Figure 9 shows that the ODP network has 512 captured the interactions of these proteins. In this pathway, the upregulation of PRKCB and REL 513 and the downregulation of NFKBIA indicate activation of REL via this pathway in the RA 514 affected synovium. It is also known that NF- $\kappa$ B proteins are activators of RANKL (TNFSF11) 515 gene expression in activated T cells (Fionda et al., 2007). Our network, through the presence of 516 DEGs in the RA synovium, shows how TCR signaling aids in activation of REL which leads to 517 RANKL expression and osteoclastogenesis. In addition, the upregulation of TNFSF11 and 518 downregulation of its competitive inhibitor TNFRSF11B marks another route to the activation of 519 REL via TRAF6. PPARG, a known inhibitor of TNFSF11-mediated osteoclastogenesis, was 520 downregulated in the ODP network. This result agrees with the findings of Li et al (Li et al., 521 2017). The upregulation of CD27 receptor is in accordance with the reports of high levels of 522 CD27 in the synovial tissue of RA patients (Tak et al., 1996). As CD27 also activates TRAF6, 
523 we speculate that the upregulation of CD27 contributes to the activation of REL via this route in

524 the RA synovium. Among the DEGs involved in the REL activation via IL1 pathway, CASP1

525 was upregulated whereas the inhibitor PELI1 was downregulated. This is balanced against the

526 upregulation of IL1RN, a competitive inhibitor of IL1R1. It is known that both the cytokines,

527 IL1 and TNF, activate NF-אB through TRAF6. However, we did not observe differential

528 regulation of the TNF pathway proteins leading to the activation of NF- $\mathrm{BB}$. On the other hand,

529 the apoptosis related proteins such as FAS and CASP8 which are downstream to TNF receptor,

530 were upregulated. Earlier studies have established that the death signaling pathways are

531 antagonized by the activity of BIRC2, BIRC3 and XIAP (Vasudevan \& Ryoo, 2015). The

532 upregulation of BIRC3 points to suppression of TNF mediated apoptosis and the activation of

$533 \mathrm{NF}-\kappa \mathrm{B}$ via TNF receptor signaling in the RA synovium. This reflects the possibility that TNF

534 signaling results in both CASP8 mediated apoptosis and BIRC3 mediated NF- $\mathrm{B}$ activation in

535 different parts of the RA synovium. The network also captures the activation of IKK by the

536 upregulated NOD2 through MAP3K7. Studies have reported that RA synovial cells express high

537 levels of NOD2 (Franca et al., 2016). We hypothesize that NOD-dependent activation of NF- $\kappa B$

538 also contributes to the osteoclastogenesis in RA synovium. All the routes that lead to activation

539 of NF- $\kappa$ B points to the canonical signaling. PEL1 is known to be a negative regulator of REL

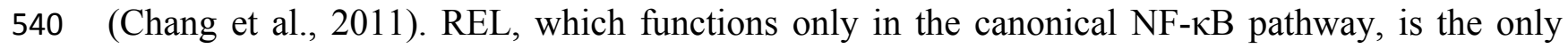

$541 \mathrm{NF}-\kappa \mathrm{B}$ protein showing differential regulation in this analysis (Shih et al., 2011). The

542 upregulation of REL, BIRC3 and PRKCB and the downregulation of PELI1 also support the

543 predominance of canonical NF- $\kappa \mathrm{B}$ signaling in RA synovium osteoclastogenesis (Lutzny et al.,

544 2013; Varfolomeev et al., 2007). 
545 The GOBP analysis revealed enrichment of TGF $\beta$ signaling pathway terms. The role of TGF $\beta$

546 signaling pathway in osteoclastogenesis is not captured in the KEGG osteoclast differentiation

547 pathway as it shows only the receptor-ligand interaction. Our network connects the TGF $\beta$

548 receptors to downstream DNA-binding proteins, of which Forkhead box proteins, SMAD3 and

549 ATF3 were downregulated. The consistent downregulation of all the DEGs in the TGF $\beta$ pathway

550 implies their negative regulatory role in the osteoclastogenesis. Although the published studies

551 support a mixed role of TGF $\beta$ pathway in the RA synovium, Karst et al showed that high

552 concentration of TGF $\beta$ is involved in the inhibition of osteoclastogenesis (Karst et al., 2004).

553 Therefore, we hypothesize that the downregulation of the TGF $\beta$ pathway produces a favourable

554 environment for osteoclastogenesis in the RA synovium.

555 A proposed model of enhanced ROS production mediating osteoclastogenesis in RA 556 synovium

557 It is known that the Nox2 complex generates ROS which act as secondary messengers during 558 osteoclast differentiation (Kang \& Kim, 2016). ROS are also known to cause activation of 559 canonical NF-кB pathway (Gloire, Legrand-Poels \& Piette, 2006). In the ODP network, the 560 upregulation of NCF1, NCF2, NCF4 and CYBA, the four components of Nox2 complex, may 561 indicate the osteoclast differentiation as well as oxidative burst by phagocytic cells in the RA 562 synovium (Rosen et al., 1995). The NCF cluster, selected by MCODE analysis, demonstrates the 563 activation of the core proteins NCF2, NCF4, CYBA and RAC1 by the shell proteins NCF1, 564 PRKCZ and PARD6G. It is known that PRKCZ is activated by $\mathrm{T}$ cell receptor (Bertrand et al., 565 2010). In our analysis, it was observed that multiple $T$ cell receptor signaling molecules were 566 upregulated. We hypothesize that the TCR signaling via PRKCZ activates NCF complex which 567 may subsequently generate ROS in the RA synovium. It is known that ROS can diffuse across 
568 cell membranes to take part in intracellular signaling (Fisher, 2009). We believe that the 569 activation of PRKCZ leading to the generation of ROS is one of the routes facilitating osteoclast

570 differentiation in RA synovium. Our network also illustrated an upregulation of the catalytic 571 subunit of PI3K, PIK3CD which is another downstream molecule of $\mathrm{T}$ cell receptor signaling.

572 This is supported by the findings of Bartok et al (Bartok et al., 2012). PI3K-AKT pathway results

573 in inhibition of the Forkhead box proteins, FOXO1 and FOXO3 (Patel \& Mohan, 2005). It was

574 shown that FOXO upregulates antioxidant enzymes that inhibit osteoclastogenesis (Bartell et al., 575 2014). In the ODP network, the downregulation of FOXO1 and FOXO3 is a possible indication 576 of the presence of ROS mediated osteoclastogenesis in RA synovium. Bartell et al (Bartell et al., 577 2014), experimentally proved the role of RANKL in the downregulation of the Forkhead box 578 proteins. In accordance with this, our analysis showed an upregulation of RANKL in the ODP 579 network. Finally, our analysis reported the upregulation of the cytokine receptor CSF1R which is 580 also required for osteoclastogenesis via PI3K-AKT pathway. The proposed model consisting of 581 all the signaling routes promoting osteoclastogenesis via generation of ROS in the RA synovium 582 is summarized in Fig. 10.

\section{Conclusion}

584 In this study, we have created a PPI network for osteoclast differentiation in the RA synovium 585 for the first time using gene expression under RA conditions from microarray experiments, 586 pathway enrichment analysis and protein protein interaction data. This network captures all the 587 signaling routes that lead to osteoclastogenesis in the synovium and depicts the roles of $\mathrm{T}$ cell

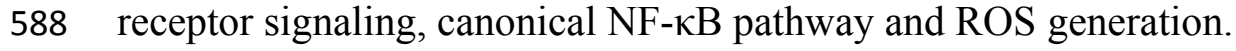


589 Data Availability: All the data generated and used for the analysis are included in this

590 manuscript and in the Supplementary information. Abbreviations used are included in Table S11.

\section{Abbreviations}

592 ACP5

593 Phosphatase - TRAP)

594 AKT

595 AMPK

596 AP1

597 BCL10

598 BIRC2

599 Apoptosis 1)

600 BIRC3

601 Apoptosis 2)

602 CARD11

603 CASP1

604 CD247

$605 \quad \mathrm{CD} 27$

606 CD28

607 CD3E
Acid Phosphatase 5, Tartrate Resistant (Tartrate-Resistant Acid

Akt Serine/Threonine Kinase 1 (protein Kinase B)

5' Adenosine Monophosphate-Activated Protein Kinase

Activator Protein 1

B Cell Cl1/Lymphoma 10

Baculoviral Iap Repeat-Containing Protein 2 (Cellular Inhibitor Of

Baculoviral Iap Repeat-Containing Protein 3 (Cellular Inhibitor Of

Caspase Recruitment Domain Family Member 11

Caspase 1

T-Cell Surface Glycoprotein CD3 Zeta Chain

T-Cell Activation Antigen CD27

T-Cell-Specific Surface Glycoprotein Cd28

T-Cell Surface Glycoprotein CD3 Epsilon Chain 
608 CD47

609 cGMP

610 CRP

611 CSF1R

612 CSK

613 CTSK

614 CYBA

615 DAVID

616 DEG

617 EASE

$618 \mathrm{ECM}$

619 ESR

620 FAS

621 FCER1G

622 FOS

623 FOSB

624 FOXO1

$625 \quad$ FOXO3
Leukocyte Surface Antigen CD47 (integrin Associated Protein)

Cyclic Guanosine Monophosphate

C-Reactive Protein

Colony Stimulating Factor 1 Receptor

C-Terminal Src Kinase

Cathepsin K

Cytochrome B-245 Alpha Chain

Database for Annotation, Visualization and Integrated Discovery

Differentially expressed gene

Expression Analysis Systematic Explorer

Extra cellular matrix

Erythrocyte Sedimentation Rate

Fas cell Surface Death Receptor (CD95)

High Affinity Immunoglobulin Epsilon Receptor Subunit Gamma 3

Fos proto-oncogene

Fosb Proto-Oncogene, Ap-1 Transcription Factor Subunit

Forkhead Box Protein O1

Forkhead Box Protein O3 
626 FYB

$627 \quad$ FZD4

628 GEO

629 GF

$630 \mathrm{GO}$

631 GOBP

632 GOMF

633 GRN

634 ID

635 IFNAR2

636 IFN $\beta$

$637 \operatorname{IgE}$

638 IGKC

639 IKK

640 IL1A

641 IL1A

642 IL1R1

643 IL1RN
Fyn Binding Protein

Frizzled Class Receptor 4

Gene Expression Omnibus

Growth Factor

Gene Ontology

Gene Ontology Biological Process

Gene Ontology Molecular Function

Gene Regulatory Network

Identifier

Interferon Alpha And Beta Receptor Subunit 2

Interferon Beta

Immunoglobulin E

Immunoglobulin Kappa Constant Region

Inhibitor Of Nuclear Factor Kappa B Kinase

Interleukin 1 Alpha (hematopoietin 1)

Interleukin 1 Alpha

Interleukin 1 Receptor Type 1

Interleukin 1 Receptor Antagonist 


\begin{tabular}{|c|c|c|}
\hline 644 & IL7R & Interleukin 7 Receptor \\
\hline 645 & INPP5D & Inositol Polyphosphate-5-Phosphatase D \\
\hline 646 & $\mathrm{IkB}$ & Nf-Kappa-B Inhibitor \\
\hline 647 & IRAK4 & Interleukin 1 Receptor Associated Kinase 4 \\
\hline 648 & ITK & I12 Inducible $\mathrm{T}$ Cell Kinase \\
\hline 649 & JAK2 & Janus Kinase 2 \\
\hline 650 & JUN & Jun proto-Oncogene, Ap-1 Transcription Factor Subunit \\
\hline 651 & JUNB & Junb Proto-Oncogene, Ap-1 Transcription Factor Subunit \\
\hline 652 & KEGG & Kyoto Encyclopedia Of Genes And Genomes \\
\hline 653 & LAT & Linker For Activation Of T Cells \\
\hline 654 & $\mathrm{LCK}$ & Lymphocyte-Specific Protein Tyrosine Kinase \\
\hline 655 & LCP2 & Lymphocyte Cytosolic Protein 2 (Sh2 Domain Containing Leukocyte \\
\hline 656 & Protein Of 76kda) & \\
\hline 657 & LRP6 & Ldl Receptor Related Protein 6 \\
\hline 658 & LYN & Lck/Yes-Related Novel Protein Tyrosine Kinase \\
\hline 659 & MAP3K7 & Mitogen-Activated Protein Kinase Kinase Kinase 7 (TGF-Beta Activated \\
\hline 660 & Kinase 1) & \\
\hline 661 & MAPK1 & Mitogen-Activated Protein Kinase 1 \\
\hline 662 & MAS5 & Microarray Suite 5.0 \\
\hline
\end{tabular}




\begin{tabular}{|c|c|c|}
\hline 663 & MYD88 & Myeloid Differentiation Primary Response 88 \\
\hline 664 & $\mathrm{NCF}$ & Neutrophil Cytosol Factor \\
\hline 665 & NCF1 & Neutrophil Cytosolic Factor 1 \\
\hline 666 & NCF2 & Neutrophil Cytosol Factor 2 \\
\hline 667 & NCF4 & Neutrophil Cytosol Factor 4 \\
\hline 668 & $\mathrm{NF}-\kappa \mathrm{B}$ & Nuclear Factor Kappa-Light-Chain-Enhancer Of Activated B Cells \\
\hline 669 & NFKBIA & Nf-kb Inhibitor Alpha \\
\hline 670 & NFKBIB & Nf-кb Inhibitor Beta \\
\hline 671 & NOD2 & Nucleotide Binding Oligomerization Domain Containing Protein 2 \\
\hline 672 & Nox2 & NADPH Oxidase 2 \\
\hline 673 & ODP & Osteoclast Differentiation Pathway \\
\hline 674 & PAG1 & Phosphoprotein Associated with Glycosphingolipid-enriched \\
\hline 675 & microdomains 1 & \\
\hline 676 & PARD6G & Par-6 Family Cell Polarity Regulator Gamma \\
\hline 677 & PELI1 & Pellino E3 Ubiquitin Protein Ligase 1 \\
\hline 678 & PI3K & Phosphatidylinositol-4,5-Bisphosphate 3-Kinase \\
\hline 679 & PIK3CD & Phosphatidylinositol-4,5-Bisphosphate 3-Kinase Catalytic Subunit Delta \\
\hline 680 & PIK3CD & Phosphatidylinositol-4,5-Bisphosphate 3-Kinase Catalytic Subunit Delta \\
\hline 681 & PKG & cGMP Dependent Protein Kinase (protein Kinase G) \\
\hline
\end{tabular}




\begin{tabular}{|c|c|c|}
\hline 682 & PLCG2 & Phospholipase C Gamma 2 \\
\hline 683 & PPARG & Peroxisome Proliferator Activated Receptor Gamma \\
\hline 684 & PPI & Protein-Protein Interaction \\
\hline 685 & PPIA & Peptidylprolyl Isomerase A (cyclophilin A) \\
\hline 686 & PPP3CA & Protein Phosphatase 3 Catalytic Subunit Alpha (calcineurin A Alpha) \\
\hline 687 & PPP3R1 & Protein Phosphatase 3 Regulatory Subunit B, Alpha (calcineurin Subunit \\
\hline 688 & B Type 1) & \\
\hline 689 & PRKCB & Protein Kinase C Beta \\
\hline 690 & PRKCQ & Protein Kinase C Theta \\
\hline 691 & PRKCZ & Protein Kinase C Zeta \\
\hline 692 & PTM & Post Translational Modification \\
\hline 693 & RA & Rheumatoid Arthritis \\
\hline 694 & $\mathrm{RAC1}$ & Rac Family Small GTPase 1 \\
\hline 695 & RANKL & Receptor Activator Of Nuclear Factor Kappa B Ligand \\
\hline 696 & RCAN1 & Regulator Of Calcineurin 1 \\
\hline 697 & REL & Rel proto-Oncogene, Nf-kb Subunit \\
\hline 698 & RMA & Robust Multiarray Average \\
\hline 699 & ROS & Reactive Oxygen Species \\
\hline 700 & RPS6KA1 & Ribosomal Protein S6 Kinase A1 \\
\hline
\end{tabular}


701 RTK

702 S100A13

703 SFRP1

704 SFRP2

705 SFRP4

706 SIRPA

707 SMAD3

708 STAT1

709 STAT2

710 STRING

711 TCR

712 TF

713 TGFB1

714 TGFB2

715 TGFB3

716 TGFBR1

717 TGFBR2

718 TGFBR3
Receptor Tyrosine Kinase

S100 Calcium-Binding Protein A13

Secreted Frizzled Related Protein 1

Secreted Frizzled Related Protein 2

Secreted Frizzled Related Protein 4

Signal Regulatory Protein Alpha

Mothers Against Decapentaplegic Homolog 3

Signal Transducer And Activator Of Transcription 1

Signal Transducer And Activator Of Transcription 2

Search Tool For The Retrieval Of Interacting Genes/Proteins

T Cell Receptor

Transcription Factor

Transforming Growth Factor Beta-1

Transforming Growth Factor Beta-2

Transforming Growth Factor Beta-3

Tgf-Beta Receptor Type-1

Tgf-Beta Receptor Type-2

Tgf-Beta Receptor Type-3 
719 TGF $\beta$

720 TLR

721 TLR3

722 TLR4

723 TNFRSF11B

724 TNFRSF1A

725 TNFSF11

726 TRAF2

727 TRAF6

$728 \mathrm{UBC}$

729 XIAP

730 ZAP70
Transforming Growth Factor Beta

Toll Like Receptor

Toll Like Receptor 3

Toll Like Receptor 4

Tnf Receptor Superfamily Member 11b (Osteoprotegerin)

Tumor Necrosis Factor Receptor 1

Tumor Necrosis Factor Superfamily Member 11 (RANKL)

TNF Receptor Associated Factor 2

TNF Receptor Associated Factor 6

Ubiquitin C

X-Linked Inhibitor Of Apoptosis

Zeta Chain Associated Protein Kinase 70

\section{References}

732

733

734

735

736

Assenov Y., Ramirez F., Schelhorn S-E., Lengauer T., Albrecht M. 2008. Computing topological parameters of biological networks. Bioinformatics (Oxford, England) 24:282-284. DOI: 10.1093/bioinformatics/btm554.

Bader GD., Hogue CWV. 2003. An automated method for finding molecular complexes in large protein interaction networks. BMC bioinformatics 4:2. 
737 Bartell SM., Kim H-N., Ambrogini E., Han L., Iyer S., Serra Ucer S., Rabinovitch P., Jilka RL., Weinstein RS.,

738 Zhao H., O’Brien CA., Manolagas SC., Almeida M. 2014. FoxO proteins restrain

739

740

741

742

743

744

745

746

747

748

749

750

751

752

753

754

755

756

757

758

759

760

osteoclastogenesis and bone resorption by attenuating $\mathrm{H} 2 \mathrm{O} 2$ accumulation. Nature communications 5:3773. DOI: 10.1038/ncomms4773.

Bartok B., Boyle DL., Liu Y., Ren P., Ball ST., Bugbee WD., Rommel C., Firestein GS. 2012. PI3 kinase delta is a key regulator of synoviocyte function in rheumatoid arthritis. The American journal of pathology 180:1906-1916. DOI: 10.1016/j.ajpath.2012.01.030.

Bertrand F., Esquerre M., Petit A-E., Rodrigues M., Duchez S., Delon J., Valitutti S. 2010. Activation of the ancestral polarity regulator protein kinase $\mathrm{C}$ zeta at the immunological synapse drives polarization of Th cell secretory machinery toward APCs. Journal of immunology (Baltimore, Md. : 1950) 185:2887-2894. DOI: 10.4049/jimmunol.1000739.

Broeren MGA., de Vries M., Bennink MB., Arntz OJ., Blom AB., Koenders MI., van Lent PLEM., van der Kraan PM., van den Berg WB., van de Loo FAJ. 2016. Disease-Regulated Gene Therapy with AntiInflammatory Interleukin-10 Under the Control of the CXCL10 Promoter for the Treatment of Rheumatoid Arthritis. Human gene therapy 27:244-254. DOI: 10.1089/hum.2015.127.

Browner NC., Sellak H., Lincoln TM. 2004. Downregulation of cGMP-dependent protein kinase expression by inflammatory cytokines in vascular smooth muscle cells. American journal of physiology. Cell physiology 287:C88-96. DOI: 10.1152/ajpcell.00039.2004.

Chang M., Jin W., Chang J-H., Xiao Y., Brittain G., Yu J., Zhou X., Wang Y-H., Cheng X., Li P., Rabinovich BA., Hwu P., Sun S-C. 2011. Peli1 negatively regulates T-cell activation and prevents autoimmunity. Nature immunology 12:1002-1009. DOI: 10.1038/ni.2090.

Davis S., Meltzer PS. 2007. GEOquery: a bridge between the Gene Expression Omnibus (GEO) and BioConductor. Bioinformatics (Oxford, England) 23:1846-1847. DOI: 10.1093/bioinformatics/btm254. 
761 Dey P., Panga V., Raghunathan S. 2016. A Cytokine Signalling Network for the Regulation of Inducible

$762 \quad$ Nitric Oxide Synthase Expression in Rheumatoid Arthritis. PloS one 11:e0161306. DOI:

$763 \quad$ 10.1371/journal.pone.0161306.

764 Dooley S., Herlitzka I., Hanselmann R., Ermis A., Henn W., Remberger K., Hopf T., Welter C. 1996.

765 Constitutive expression of c-fos and c-jun, overexpression of ets-2, and reduced expression of

766 metastasis suppressor gene $\mathrm{nm} 23-\mathrm{H} 1$ in rheumatoid arthritis. Annals of the rheumatic diseases

$767 \quad 55: 298-304$.

768 Edgar R., Domrachev M., Lash AE. 2002. Gene Expression Omnibus: NCBI gene expression and

769 hybridization array data repository. Nucleic acids research 30:207-210.

770 Expansion of the Gene Ontology knowledgebase and resources. 2017. Nucleic acids research 45:D331-

771 D338. DOI: 10.1093/nar/gkw1108.

772 Fionda C., Nappi F., Piccoli M., Frati L., Santoni A., Cippitelli M. 2007. 15-Deoxy- $\Delta^{12,14-P r o s t a g l a n d i n ~ J 2}$ Negatively Regulates <em>rankl</em> Gene Expression in Activated T Lymphocytes: Role of NFKB and Early Growth Response Transcription Factors. The Journal of Immunology 178:4039. DOI:

Fisher AB. 2009. Redox Signaling Across Cell Membranes. Antioxidants \& Redox Signaling 11:1349-1356. DOI: $10.1089 /$ ars.2008.2378.

Franca R., Vieira SM., Talbot J., Peres RS., Pinto LG., Zamboni DS., Louzada-Junior P., Cunha FQ., Cunha TM. 2016. Expression and activity of NOD1 and NOD2/RIPK2 signalling in mononuclear cells from patients with rheumatoid arthritis. Scandinavian journal of rheumatology 45:8-12. DOI: 10.3109/03009742.2015.1047403.

Gautier L., Cope L., Bolstad BM., Irizarry RA. 2004. affy--analysis of Affymetrix GeneChip data at the probe level. Bioinformatics (Oxford, England) 20:307-315. DOI: 10.1093/bioinformatics/btg405. 
784 Gloire G., Legrand-Poels S., Piette J. 2006. NF-kappaB activation by reactive oxygen species: fifteen years

785

786

787

788

789

790

791

792

793

794

795

796

797

798

799

800

801

802

803

804

805 later. Biochemical pharmacology 72:1493-1505. DOI: 10.1016/j.bcp.2006.04.011.

Grabiec AM., Angiolilli C., Hartkamp LM., van Baarsen LGM., Tak PP., Reedquist KA. 2015. JNKdependent downregulation of FoxO1 is required to promote the survival of fibroblast-like synoviocytes in rheumatoid arthritis. Annals of the rheumatic diseases 74:1763-1771. DOI: 10.1136/annrheumdis-2013-203610.

Gravallese EM., Harada Y., Wang JT., Gorn AH., Thornhill TS., Goldring SR. 1998. Identification of cell types responsible for bone resorption in rheumatoid arthritis and juvenile rheumatoid arthritis. The American journal of pathology 152:943-951.

Grigoriadis AE., Wang ZQ., Cecchini MG., Hofstetter W., Felix R., Fleisch HA., Wagner EF. 1994. c-Fos: a key regulator of osteoclast-macrophage lineage determination and bone remodeling. Science (New York, N.Y.) 266:443-448.

Gruber B., Ballan D., Gorevic PD. 1988. IgE rheumatoid factors: quantification in synovial fluid and ability to induce synovial mast cell histamine release. Clinical and Experimental Immunology 71:289294.

Hao R., Du H., Guo L., Tian F., An N., Yang T., Wang C., Wang B., Zhou Z. 2017. Identification of dysregulated genes in rheumatoid arthritis based on bioinformatics analysis. PeerJ 5:e3078. DOI: 10.7717/peerj.3078.

Hosack DA., Dennis G., Sherman BT., Lane HC., Lempicki RA. 2003. Identifying biological themes within lists of genes with EASE. Genome Biology 4:P4. DOI: 10.1186/gb-2003-4-6-p4.

Huang DW., Sherman BT., Lempicki RA. 2009a. Systematic and integrative analysis of large gene lists using DAVID bioinformatics resources. Nature protocols 4:44-57. DOI: 10.1038/nprot.2008.211. 
806 Huang DW., Sherman BT., Lempicki RA. 2009b. Bioinformatics enrichment tools: paths toward the

807

808

809

810

811

812

813

814

815

816

817

818

819

820

821

822

823

824

825

826

827

828

829

comprehensive functional analysis of large gene lists. Nucleic acids research 37:1-13. DOI: 10.1093/nar/gkn923.

Huber R., Hummert C., Gausmann U., Pohlers D., Koczan D., Guthke R., Kinne RW. 2008. Identification of intra-group, inter-individual, and gene-specific variances in mRNA expression profiles in the rheumatoid arthritis synovial membrane. Arthritis research \& therapy 10:R98. DOI: 10.1186/ar2485.

Jeong H., Baek SY., Kim SW., Eun YH., Kim IY., Kim H., Lee J., Koh E-M., Cha H-S. 2017. Comorbidities of rheumatoid arthritis: Results from the Korean National Health and Nutrition Examination Survey. PloS one 12:e0176260. DOI: 10.1371/journal.pone.0176260.

Jung SM., Kim KW., Yang C-W., Park S-H., Ju JH. 2014. Cytokine-Mediated Bone Destruction in Rheumatoid Arthritis. Journal of Immunology Research 2014. DOI: 10.1155/2014/263625.

Kanehisa M., Furumichi M., Tanabe M., Sato Y., Morishima K. 2017. KEGG: new perspectives on genomes, pathways, diseases and drugs. Nucleic acids research 45:D353-D361. DOI: 10.1093/nar/gkw1092.

Kang IS., Kim C. 2016. NADPH oxidase gp91(phox) contributes to RANKL-induced osteoclast differentiation by upregulating NFATc1. Scientific reports 6:38014. DOI: 10.1038/srep38014.

Karst M., Gorny G., Galvin RJS., Oursler MJ. 2004. Roles of stromal cell RANKL, OPG, and M-CSF expression in biphasic TGF-beta regulation of osteoclast differentiation. Journal of cellular physiology 200:99-106. DOI: 10.1002/jcp.20036.

Kinne RW., Boehm S., Iftner T., Aigner T., Vornehm S., Weseloh G., Bravo R., Emmrich F., Kroczek RA. 1995. Synovial fibroblast-like cells strongly express jun-B and C-fos proto-oncogenes in rheumatoid- and osteoarthritis. Scandinavian journal of rheumatology. Supplement 101:121125. 
830 Kupfer P., Huber R., Weber M., Vlaic S., Haupl T., Koczan D., Guthke R., Kinne RW. 2014. Novel

831

832

835

836

837

838

839

840

841

842

843

844

845

846

847

848

849

850

851

852

853 application of multi-stimuli network inference to synovial fibroblasts of rheumatoid arthritis patients. BMC medical genomics 7:40. DOI: 10.1186/1755-8794-7-40.

Lee H., Kashiwakura J., Matsuda A., Watanabe Y., Sakamoto-Sasaki T., Matsumoto K., Hashimoto N., Saito S., Ohmori K., Nagaoka M., Tokuhashi Y., Ra C., Okayama Y. 2013. Activation of human synovial mast cells from rheumatoid arthritis or osteoarthritis patients in response to aggregated IgG through Fcgamma receptor I and Fcgamma receptor II. Arthritis and rheumatism 65:109-119. DOI: 10.1002/art.37741.

Lee H-M., Sugino H., Aoki C., Shimaoka Y., Suzuki R., Ochi K., Ochi T., Nishimoto N. 2011. Abnormal networks of immune response-related molecules in bone marrow cells from patients with rheumatoid arthritis as revealed by DNA microarray analysis. Arthritis research \& therapy 13:R89. DOI: 10.1186/ar3364.

Li X-F., Sun Y-Y., Bao J., Chen X., Li Y-H., Yang Y., Zhang L., Huang C., Wu B-M., Meng X-M., Li J. 2017. Functional role of PPAR-gamma on the proliferation and migration of fibroblast-like synoviocytes in rheumatoid arthritis. Scientific reports 7:12671. DOI: 10.1038/s41598-01712570-6.

Lories RJ., Corr M., Lane NE. 2013. To Wnt or not to Wnt: the bone and joint health dilemma. Nature reviews. Rheumatology 9:328-339. DOI: 10.1038/nrrheum.2013.25.

Ludikhuize J., de Launay D., Groot D., Smeets TJM., Vinkenoog M., Sanders ME., Tas SW., Tak PP., Reedquist KA. 2007. Inhibition of forkhead box class O family member transcription factors in rheumatoid synovial tissue. Arthritis and rheumatism 56:2180-2191. DOI: 10.1002/art.22653.

Lutzny G., Kocher T., Schmidt-Supprian M., Rudelius M., Klein-Hitpass L., Finch AJ., Dürig J., Wagner M., Haferlach C., KohImann A., Schnittger S., Seifert M., Wanninger S., Zaborsky N., Oostendorp R., Ruland J., Leitges M., Kuhnt T., Schäfer Y., Lampl B., Peschel C., Egle A., Ringshausen I. 2013. 

Survival of Chronic Lymphocytic Leukemia B Cells In Vivo. Cancer Cell 23:77-92. DOI: 10.1016/j.ccr.2012.12.003.

McInnes IB., Schett G. 2007. Cytokines in the pathogenesis of rheumatoid arthritis. Nature reviews. Immunology 7:429-442. DOI: 10.1038/nri2094.

McInnes IB., Schett G. 2011. The pathogenesis of rheumatoid arthritis. The New England journal of medicine 365:2205-2219. DOI: 10.1056/NEJMra1004965.

Miao C., Yang Y., He X., Li X., Huang C., Huang Y., Zhang L., Lv X-W., Jin Y., Li J. 2013. Wnt signaling pathway in rheumatoid arthritis, with special emphasis on the different roles in synovial inflammation and bone remodeling. Cellular signalling 25:2069-2078. DOI: 10.1016/j.cellsig.2013.04.002.

865

866

867

868 869

Nevius E., Gomes AC., Pereira JP. 2016. A comprehensive review of inflammatory cell migration in rheumatoid arthritis. Clinical reviews in allergy \& immunology 51:59-78. DOI: 10.1007/s12016015-8520-9.

Otterness IG. 1994. The value of C-reactive protein measurement in rheumatoid arthritis. Seminars in arthritis and rheumatism 24:91-104.

Patel RK., Mohan C. 2005. PI3K/AKT signaling and systemic autoimmunity. Immunologic research 31:4755. DOI: 10.1385/IR:31:1:47.

Pepper SD., Saunders EK., Edwards LE., Wilson CL., Miller CJ. 2007. The utility of MAS5 expression summary and detection call algorithms. BMC Bioinformatics 8:273. DOI: 10.1186/1471-2105-8273.

R Core Team. 2017. R: A language and environment for statistical computing. R Foundation for Statistical Computing, Vienna, Austria. URL https://www.R-project.org/. 
877 Raker VK., Becker C., Steinbrink K. 2016. The cAMP Pathway as Therapeutic Target in Autoimmune and 878 Inflammatory Diseases. Frontiers in Immunology 7. DOI: 10.3389/fimmu.2016.00123.

879 Rosen GM., Pou S., Ramos CL., Cohen MS., Britigan BE. 1995. Free radicals and phagocytic cells. FASEB 880 journal : official publication of the Federation of American Societies for Experimental Biology

881 9:200-209.

882

Sams M., Olsen MA., Joshi R., Ranganathan P. 2015. Staphylococcus aureus sepsis in rheumatoid 883 arthritis. Rheumatology international 35:1503-1510. DOI: 10.1007/s00296-015-3239-8.

Schett G. 2007. Cells of the synovium in rheumatoid arthritis. Osteoclasts. Arthritis research \& therapy 885 9:203. DOI: 10.1186/ar2110.

886

Shannon P., Markiel A., Ozier O., Baliga NS., Wang JT., Ramage D., Amin N., Schwikowski B., Ideker T. 2003. Cytoscape: a software environment for integrated models of biomolecular interaction networks. Genome research 13:2498-2504. DOI: 10.1101/gr.1239303.

Shih VF-S., Tsui R., Caldwell A., Hoffmann A. 2011. A single NFkB system for both canonical and non-

890 canonical signaling. Cell Research 21:86-102. DOI: 10.1038/cr.2010.161.

891

892

893

894

895

896

897 898

899

900

Sommer K., Guo B., Pomerantz JL., Bandaranayake AD., Moreno-Garcia ME., Ovechkina YL., Rawlings DJ. 2005. Phosphorylation of the CARMA1 linker controls NF-kappaB activation. Immunity 23:561574. DOI: 10.1016/j.immuni.2005.09.014.

Speirs C., Williams JJL., Riches K., Salt IP., Palmer TM. 2018. Linking energy sensing to suppression of JAKSTAT signalling: A potential route for repurposing AMPK activators? Pharmacological research 128:88-100. DOI: 10.1016/j.phrs.2017.10.001.

Szamel M., Bartels F., Resch K. 1993. Cyclosporin A inhibits T cell receptor-induced interleukin-2 synthesis of human T lymphocytes by selectively preventing a transmembrane signal transduction pathway leading to sustained activation of a protein kinase $\mathrm{C}$ isoenzyme, protein kinase. European journal of immunology 23:3072-3081. DOI: 10.1002/eji.1830231205. 
901 Szklarczyk D., Franceschini A., Wyder S., Forslund K., Heller D., Huerta-Cepas J., Simonovic M., Roth A., 902 Santos A., Tsafou KP., Kuhn M., Bork P., Jensen LJ., von Mering C. 2015. STRING v10: protein903 protein interaction networks, integrated over the tree of life. Nucleic acids research 43:D447-

904 452. DOI: 10.1093/nar/gku1003.

905

906

907

908

909

910

911

912

913

914

915

916

917

918

919

920

921

922

923
AJ., Breedveld FC. 1996. Expression of the activation antigen CD27 in rheumatoid arthritis. Clinical immunology and immunopathology 80:129-138.

Tenenbaum D. 2017. KEGGREST: Client-side REST access to KEGG. R package version 1.14.1.

Tetlow LC., Woolley DE. 1995. Mast cells, cytokines, and metalloproteinases at the rheumatoid lesion: dual immunolocalisation studies. Annals of the rheumatic diseases 54:896-903.

Turvey SE., Durandy A., Fischer A., Fung S-Y., Geha RS., Gewies A., Giese T., Greil J., Keller B., McKinnon ML., Neven B., Rozmus J., Ruland J., Snow AL., Stepensky P., Warnatz K. 2014. The CARD11BCL10-MALT1 (CBM) signalosome complex: Stepping into the limelight of human primary immunodeficiency. The Journal of allergy and clinical immunology 134:276-284. DOI: 10.1016/j.jaci.2014.06.015.

Ungethuem U., Haeupl T., Witt H., Koczan D., Krenn V., Huber H., von Helversen TM., Drungowski M., Seyfert C., Zacher J., Pruss A., Neidel J., Lehrach H., Thiesen HJ., Ruiz P., Blass S. 2010. Molecular signatures and new candidates to target the pathogenesis of rheumatoid arthritis. Physiological genomics 42A:267-282. DOI: 10.1152/physiolgenomics.00004.2010.

Varfolomeev E., Blankenship JW., Wayson SM., Fedorova AV., Kayagaki N., Garg P., Zobel K., Dynek JN., Elliott LO., Wallweber HJA., Flygare JA., Fairbrother WJ., Deshayes K., Dixit VM., Vucic D. 2007. IAP antagonists induce autoubiquitination of c-IAPs, NF-kappaB activation, and TNFalphadependent apoptosis. Cell 131:669-681. DOI: 10.1016/j.cell.2007.10.030. 
924 Vasudevan D., Ryoo HD. 2015. Regulation of Cell Death by IAPs and Their Antagonists. Current topics in 925 developmental biology 114:185-208. DOI: 10.1016/bs.ctdb.2015.07.026.

926 Wang H., Guo J., Jiang J., Wu W., Chang X., Zhou H., Li Z., Zhao J. 2017. New genes associated with

927

928

929

930

931

932

933

934

935

936

937

938

939

940

941

942

943

944

945

946 rheumatoid arthritis identified by gene expression profiling. International journal of immunogenetics 44:107-113. DOI: 10.1111/iji.12313.

Wang P., Heitman J. 2005. The cyclophilins. Genome Biology 6:226. DOI: 10.1186/gb-2005-6-7-226.

Wetteland P., Roger M., Solberg HE., Iversen OH. 1996. Population-based erythrocyte sedimentation rates in 3910 subjectively healthy Norwegian adults. A statistical study based on men and women from the Oslo area. Journal of internal medicine 240:125-131.

Wilson CL., Miller CJ. 2005. Simpleaffy: a BioConductor package for Affymetrix Quality Control and data analysis. Bioinformatics (Oxford, England) 21:3683-3685. DOI: 10.1093/bioinformatics/bti605.

Wishart DS., Feunang YD., Guo AC., Lo EJ., Marcu A., Grant JR., Sajed T., Johnson D., Li C., Sayeeda Z., Assempour N., Iynkkaran I., Liu Y., Maciejewski A., Gale N., Wilson A., Chin L., Cummings R., Le D., Pon A., Knox C., Wilson M. 2018. DrugBank 5.0: a major update to the DrugBank database for 2018. Nucleic acids research 46:D1074-D1082. DOI: 10.1093/nar/gkx1037.

Woetzel D., Huber R., Kupfer P., Pohlers D., Pfaff M., Driesch D., Haupl T., Koczan D., Stiehl P., Guthke R., Kinne RW. 2014. Identification of rheumatoid arthritis and osteoarthritis patients by transcriptome-based rule set generation. Arthritis research \& therapy 16:R84. DOI: 10.1186/ar4526.

Wu G., Zhu L., Dent JE., Nardini C. 2010. A comprehensive molecular interaction map for rheumatoid arthritis. PloS one 5:e10137. DOI: 10.1371/journal.pone.0010137.

Xiong Q., Zhang L., Ge W., Tang P. 2016. The roles of interferons in osteoclasts and osteoclastogenesis. Joint, bone, spine : revue du rhumatisme 83:276-281. DOI: 10.1016/j.jbspin.2015.07.010. 
947 You S., Yoo S-A., Choi S., Kim J-Y., Park S-J., Ji JD., Kim T-H., Kim K-J., Cho C-S., Hwang D., Kim W-U. 2014.

$948 \quad$ Identification of key regulators for the migration and invasion of rheumatoid synoviocytes

949 through a systems approach. Proceedings of the National Academy of Sciences of the United

$950 \quad$ States of America 111:550-555. DOI: 10.1073/pnas.1311239111.

951 Zhu Y., Davis S., Stephens R., Meltzer PS., Chen Y. 2008. GEOmetadb: powerful alternative search engine

952 for the Gene Expression Omnibus. Bioinformatics (Oxford, England) 24:2798-2800. DOI:

$953 \quad 10.1093 /$ bioinformatics/btn520.

954 


\section{Table $\mathbf{1}$ (on next page)}

The details of the databases used in this study.

The name and the reference of the database is listed in the column named "Database". The type of data used from the database and the features of the database are described in the table. The rationale for using the data from each of the databases in our study is included in the table. 


\begin{tabular}{|c|c|c|c|}
\hline Database & $\begin{array}{l}\text { Type of data } \\
\text { obtained for } \\
\text { this study }\end{array}$ & Features & Rationale \\
\hline $\begin{array}{l}\text { GEO } \\
\text { (Edgar, Domrachev } \\
\text { \& Lash, 2002) }\end{array}$ & $\begin{array}{l}\text { microarray } \\
\text { gene } \\
\text { expression data }\end{array}$ & $\begin{array}{l}\text { GEO is a public } \\
\text { repository with easy } \\
\text { access to high } \\
\text { throughput data, } \\
\text { including microarray } \\
\text { data and related } \\
\text { metadata such as } \\
\text { tissue type, disease } \\
\text { state etc. }\end{array}$ & $\begin{array}{l}\text { Microarray data from } \\
\text { GEO database was used to } \\
\text { identify DEGs in the RA } \\
\text { synovium }\end{array}$ \\
\hline $\begin{array}{l}\text { DAVID - Gene ID } \\
\text { conversion tool } \\
\text { (Huang, Sherman } \\
\text { \& Lempicki, } \\
\text { 2009b) (Huang, } \\
\text { Sherman \& } \\
\text { Lempicki, 2009a) }\end{array}$ & Gene ID types & $\begin{array}{l}\text { The DAVID } \\
\text { knowledge base } \\
\text { supports conversion } \\
\text { between more than } 20 \\
\text { gene ID types, } \\
\text { including Affymetrix } \\
\text { probe IDs. }\end{array}$ & $\begin{array}{l}\text { The DAVID gene ID } \\
\text { conversion table was used } \\
\text { to convert Affymetrix } \\
\text { probe IDs to Entrez IDs. }\end{array}$ \\
\hline $\begin{array}{l}\text { KEGG pathway } \\
\text { (Kanehisa et al., } \\
2017 \text { ) }\end{array}$ & $\begin{array}{l}\text { molecular } \\
\text { pathways }\end{array}$ & $\begin{array}{l}\text { KEGG pathways are } \\
\text { manually drawn and } \\
\text { frequently updated. } \\
\text { References are } \\
\text { provided for each } \\
\text { pathway. }\end{array}$ & $\begin{array}{l}\text { The KEGG pathway } \\
\text { database was used to } \\
\text { identify the enriched } \\
\text { pathways from the list of } \\
\text { DEGs. }\end{array}$ \\
\hline $\begin{array}{l}\text { String (v10) } \\
\text { (Szklarczyk et al., } \\
\text { 2015) }\end{array}$ & $\begin{array}{l}\text { protein-protein } \\
\text { interaction }\end{array}$ & $\begin{array}{l}\text { String integrates } \\
\text { information from } \\
\text { several sources } \\
\text { including } \\
\text { experimental results } \\
\text { from literature, and } \\
\text { provides a confidence } \\
\text { score for the } \\
\text { interaction. }\end{array}$ & $\begin{array}{l}\text { The String database was } \\
\text { used to identify the } \\
\text { proteins that directly } \\
\text { interacted with KEGG } \\
\text { osteoclast differentiation } \\
\text { pathway proteins. These } \\
\text { proteins (KEGG } \\
\text { osteoclast differentiation } \\
\text { pathway proteins and their } \\
\text { interactors) were used to } \\
\text { create a PPI network for } \\
\text { osteoclast differentiation. }\end{array}$ \\
\hline $\begin{array}{l}\text { Gene Ontology } \\
\text { ("Expansion of the } \\
\text { Gene Ontology } \\
\text { knowledgebase and }\end{array}$ & $\begin{array}{l}\text { functional } \\
\text { annotation }\end{array}$ & $\begin{array}{l}\text { Gene Ontology } \\
\text { annotation associates } \\
\text { genes to specific } \\
\text { functional terms. A }\end{array}$ & $\begin{array}{l}\text { GO enrichment was used } \\
\text { to identify the functions } \\
\text { associated with the } \\
\text { proteins in the osteoclast }\end{array}$ \\
\hline
\end{tabular}




\begin{tabular}{|l|l|l|l|}
\hline resources.," 2017) & $\begin{array}{l}\text { GO enrichment } \\
\text { analysis provides } \\
\text { information about } \\
\text { functions that a set of } \\
\text { genes may be involved } \\
\text { in. }\end{array}$ & $\begin{array}{l}\text { differentiation PPI } \\
\text { network. }\end{array}$ \\
\hline $\begin{array}{l}\text { DrugBank } \\
\text { (Wishart et al., }\end{array}$ & drug targets & $\begin{array}{l}\text { DrugBank provides } \\
\text { comprehensive } \\
\text { information of drug } \\
\text { targets and drug types } \\
\text { (small molecule, } \\
\text { biologics } \text { etc.) }\end{array}$ & $\begin{array}{l}\text { DrugBank was used to } \\
\text { identify proteins in the } \\
\text { network that are targets of } \\
\text { RA drugs. }\end{array}$ \\
\hline
\end{tabular}

2 


\section{Table 2 (on next page)}

The details of the microarray datasets from GEO repository used in our study

The accession number and the reference of the datasets is listed in the column named "Accession Number". The title of the Affymetrix platform used by the particular dataset in included in the "Platform" column of the table. The information on the number of the RA patients and healthy controls used in each dataset are included in this table. Gender distribution is provided for the datasets GSE12021(U133A) and 12021 (U133B). 


\begin{tabular}{|l|l|l|l|}
\hline Accession Number & Platform control & $\begin{array}{l}\text { Rheumatoid arthritis } \\
\text { samples }\end{array}$ & $\begin{array}{l}\text { Healthy } \\
\text { samples }\end{array}$ \\
\hline $\begin{array}{l}\text { GSE1919(Ungethue } \\
\text { m et al., 2010) }\end{array}$ & $\begin{array}{l}\text { Affymetrix Human } \\
\text { Genome U95A Array }\end{array}$ & 5 & 5 \\
\hline GSE7307 & $\begin{array}{l}\text { Affymetrix Human } \\
\text { Genome U133 Plus } \\
\text { 2.0 Array }\end{array}$ & 5 & 9 \\
\hline $\begin{array}{l}\text { GSE12021(Huber et } \\
\text { al., 2008) }\end{array}$ & $\begin{array}{l}\text { Affymetrix Human } \\
\text { Genome U133A } \\
\text { Array }\end{array}$ & $12[3 \mathrm{~m} / 9 \mathrm{f}]$ & $9[7 \mathrm{~m} / 2 \mathrm{f}]$ \\
\hline $\begin{array}{l}\text { Affymetrix Human } \\
\text { Genome U133B } \\
\text { Array }\end{array}$ & $12[3 \mathrm{~m} / 9 \mathrm{f}]$ & $4[3 \mathrm{~m} / 1 \mathrm{f}]$ \\
\hline $\begin{array}{l}\text { GSE55235(Woetzel } \\
\text { et al., 2014) }\end{array}$ & $\begin{array}{l}\text { Affymetrix Human } \\
\text { Genome U133A } \\
\text { Array }\end{array}$ & 10 & 10 \\
\hline $\begin{array}{l}\text { GSE55457(Woetzel } \\
\text { et al., 2014) }\end{array}$ & $\begin{array}{l}\text { Affymetrix Human } \\
\text { Genome U133A } \\
\text { Array }\end{array}$ & 13 & 10 \\
\hline $\begin{array}{l}\text { GSE77298(Broeren } \\
\text { et al., 2016) }\end{array}$ & $\begin{array}{l}\text { Affymetrix Human } \\
\text { Genome U133 Plus } \\
\text { 2.0 Array }\end{array}$ & 16 & 7 \\
\hline
\end{tabular}




\section{Table 3 (on next page)}

Datasets showing downregulation of AP1 proteins in the RA synovium.

This table includes the information about the downregulation of the AP1 proteins as obtained by different microarray datasets used in our study. 


\begin{tabular}{|l|l|l|l|}
\hline Dataset & FOSB & JUN & JUNB \\
\hline GSE1919 & Downregulation & No differential & No differential \\
& & regulation & regulation \\
\hline GSE7307 & No differential & Downregulation & No differential \\
\hline GSE12021 [U133A] & Downregulation & Downregulation & Downregulation \\
\hline GSE55235 & Downregulation & Downregulation & Downregulation \\
\hline GSE55457 & Downregulation & Downregulation & Downregulation \\
\hline
\end{tabular}

1 


\section{Table 4(on next page)}

Upregulated signaling pathways in the RA synovium and their KEGG categories.

The numbers prefixed with "hsa" are the KEGG identifiers for each pathway. The KEGG pathway term name along with the KEGG pathway identifier is listed in the column named "Pathways". The "Fold enrichment" is calculated based on the number of upregulated genes which belong to the KEGG pathway term ("Count"), total number of upregulated genes which are part of the KEGG pathway database ("List Total"), total number of genes that belong to the KEGG Pathway database ("Population Total") and number of the KEGG Pathway database genes which are part of the KEGG pathway term ("Population Hits"). Precisely, the "Fold enrichment" is the proportion of "Count"| "List Total" to "Population Hits"/ "Population Total" The "EASE score" represents the significance of obtaining "Count" genes in the "List Total" for the given KEGG pathway term which has "Population Hits" genes in the background "Population Total". 


\begin{tabular}{|c|c|c|c|}
\hline Pathways & KEGG Categories & Fold enrichment & EASE score \\
\hline 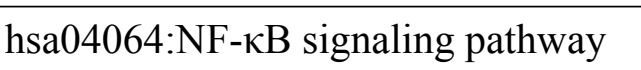 & Signal transduction & 3.92 & $6.25 \mathrm{e}^{-9}$ \\
\hline hsa04664:Fc- $\varepsilon$ RI signaling pathway & Immune system & 3.19 & $8.96 \mathrm{e}^{-5}$ \\
\hline $\begin{array}{l}\text { hsa04621:NOD-like receptor } \\
\text { signaling pathway }\end{array}$ & Immune system & 3.11 & $6.68 \mathrm{e}^{-4}$ \\
\hline $\begin{array}{l}\text { hsa04662:B cell receptor signaling } \\
\text { pathway }\end{array}$ & Immune system & 3.05 & $1.53 \mathrm{e}^{-4}$ \\
\hline $\begin{array}{l}\text { hsa04620:Toll-like receptor signaling } \\
\text { pathway }\end{array}$ & Immune system & 2.89 & $1.35 \mathrm{e}^{-5}$ \\
\hline $\begin{array}{l}\text { hsa04062:Chemokine signaling } \\
\text { pathway }\end{array}$ & Immune system & 2.82 & $4.96 \mathrm{e}^{-9}$ \\
\hline $\begin{array}{l}\text { hsa04660:T cell receptor signaling } \\
\text { pathway }\end{array}$ & Immune system & 2.30 & $1.69 \mathrm{e}^{-3}$ \\
\hline $\begin{array}{l}\text { hsa04630:JAK-STAT signaling } \\
\text { pathway }\end{array}$ & Signal transduction & 1.96 & $4.45 \mathrm{e}^{-3}$ \\
\hline
\end{tabular}

1 


\section{Table 5 (on next page)}

Downregulated signaling pathways in the RA synovium and their KEGG categories.

The numbers prefixed with "hsa" are the KEGG identifiers for each pathway. The KEGG pathway term name along with the KEGG pathway identifier is listed in the column named "Pathways". The "Fold enrichment" is calculated based on the number of downregulated genes which belong to the KEGG pathway term ("Count"), total number of downregulated genes which are part of the KEGG pathway database ("List Total"), total number of genes that belong to the KEGG Pathway database ("Population Total") and number of the KEGG Pathway database genes which are part of the KEGG pathway term ("Population Hits"). Precisely, the "Fold enrichment" is the proportion of "Count"/ "List Total" to "Population Hits"/ "Population Total" The "EASE score" represents the significance of obtaining "count" genes in the "List Total" for the given KEGG pathway term which has "Population Hits" genes in the background "Population Total". 


\begin{tabular}{|l|l|l|l|}
\hline Pathways & KEGG Categories & Fold enrichment & EASE score \\
\hline $\begin{array}{l}\text { hsa04350:TGF-beta signaling } \\
\text { pathway }\end{array}$ & Signal transduction & 2.42 & $9.49 \mathrm{e}^{-3}$ \\
\hline $\begin{array}{l}\text { hsa04152:AMPK signaling } \\
\text { pathway }\end{array}$ & Signal transduction & 2.30 & $2.56 \mathrm{e}^{-3}$ \\
\hline $\begin{array}{l}\text { hsa04068:FoxO signaling } \\
\text { pathway }\end{array}$ & Signal transduction & 2.09 & $6.57 \mathrm{e}^{-3}$ \\
\hline $\begin{array}{l}\text { hsa04022:cGMP-PKG signaling } \\
\text { pathway }\end{array}$ & Signal transduction & 1.90 & $9.85 \mathrm{e}^{-3}$ \\
\hline hsa04310:Wnt signaling pathway & Signal transduction & 1.83 & $3.26 \mathrm{e}^{-2}$ \\
\hline $\begin{array}{l}\text { hsa04024:cAMP signaling } \\
\text { pathway }\end{array}$ & Signal transduction & 1.62 & $3.27 \mathrm{e}^{-2}$ \\
\hline $\begin{array}{l}\text { hsa04010:MAPK signaling } \\
\text { pathway }\end{array}$ & Signal transduction & 1.55 & \\
\hline
\end{tabular}




\section{Figure 1}

The workflow.

\section{(A). Selection of a KEGG pathway representing a phenotype exhibited by the RA}

synovium. The differentially expressed genes in the RA synovium were identified from the analysis of the microarray datasets obtained from GEO database. A KEGG pathway enrichment analysis was performed on the differentially expressed gene lists. The enriched pathways were categorized into process and signaling pathways. Based on the shared differentially expressed genes, a pathway overlap network was created. Osteoclast differentiation pathway was selected as the pathway of interest as it overlapped with most number of signaling pathways. (B). Construction and analysis of the osteoclast differentiation network. The proteins belonging to the KEGG osteoclast differentiation pathway were termed as "core proteins". The core proteins were used as an input to the String DB to obtain the proteins interacting with them (first shell proteins). The interactions among all the proteins (core and first shell) were also extracted from String DB. The interactions were validated using PubMed. The directions of the protein interactions were also obtained. The proteins and the interactions were used to construct a network for osteoclast differentiation. The gene ontology term enrichment analysis was performed on the network. Differentially regulated genes were indicated in the network. The gene ontology term enrichment analysis and the differentially regulated genes were used to identify the important protein interactions that lead to osteoclast differentiation in the RA synovium. The protein targets of the drugs used in RA treatment were obtained from DrugBank database and were indicated in the network. 


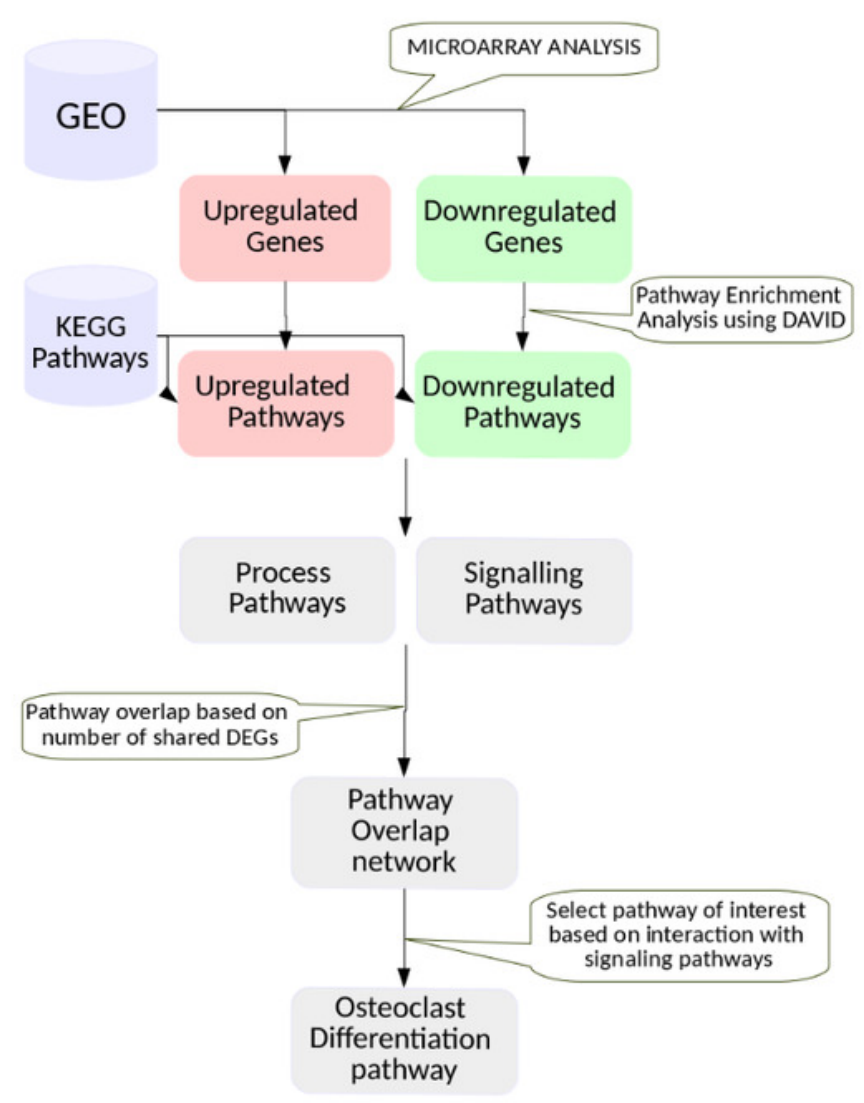

A

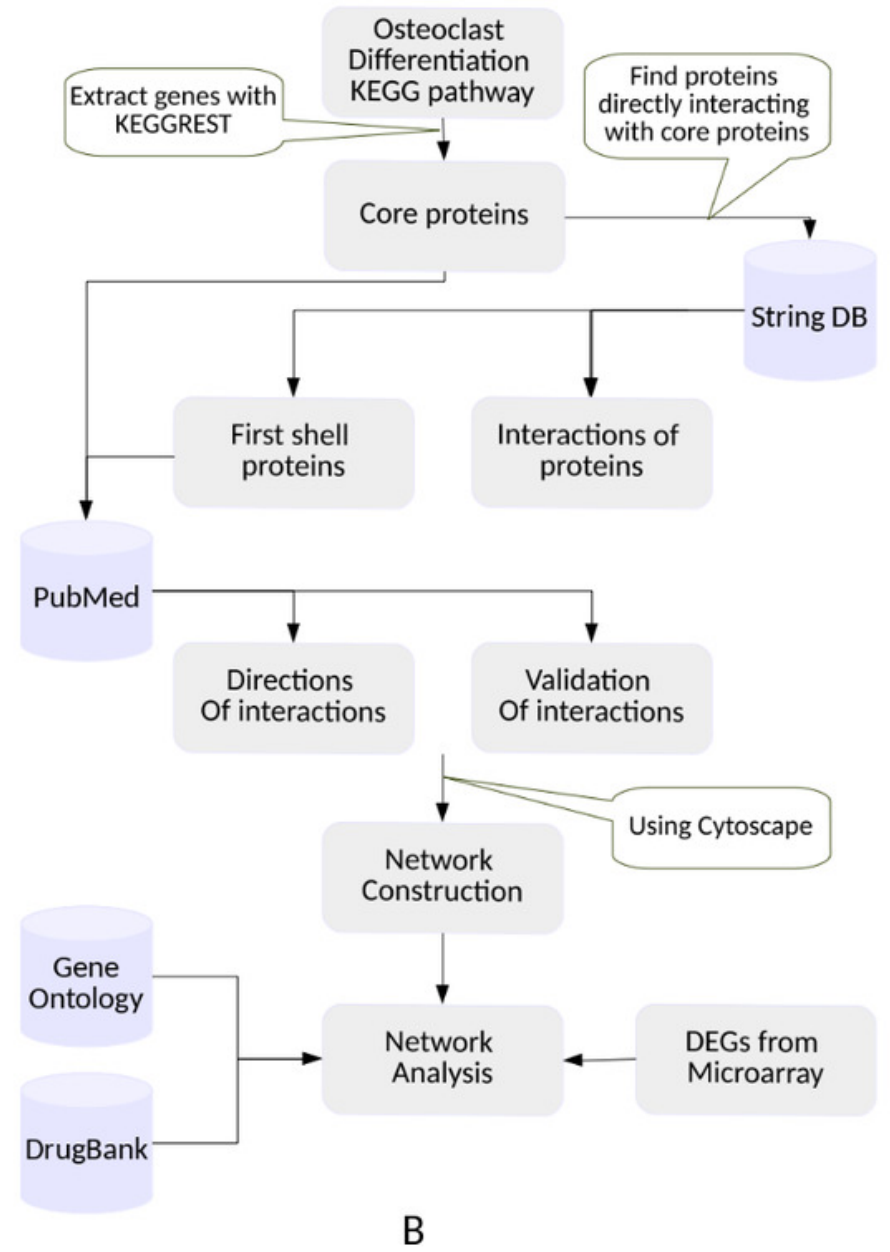




\section{Figure 2}

Number of up and downregulated genes obtained based on the selection criteria.

The numbers on $x$-axis represent the following: " 1 ": selection of the genes at least once by the algorithm MAS5 and RMA, "2": selection of the genes at least twice by both the algorithms, "3": selection of the genes at least thrice by both the algorithms and so on. The $y$-axis represents the number of selected up and downregulated genes. The number of differentially expressed genes selected at least once by both the algorithms are used in this study. 


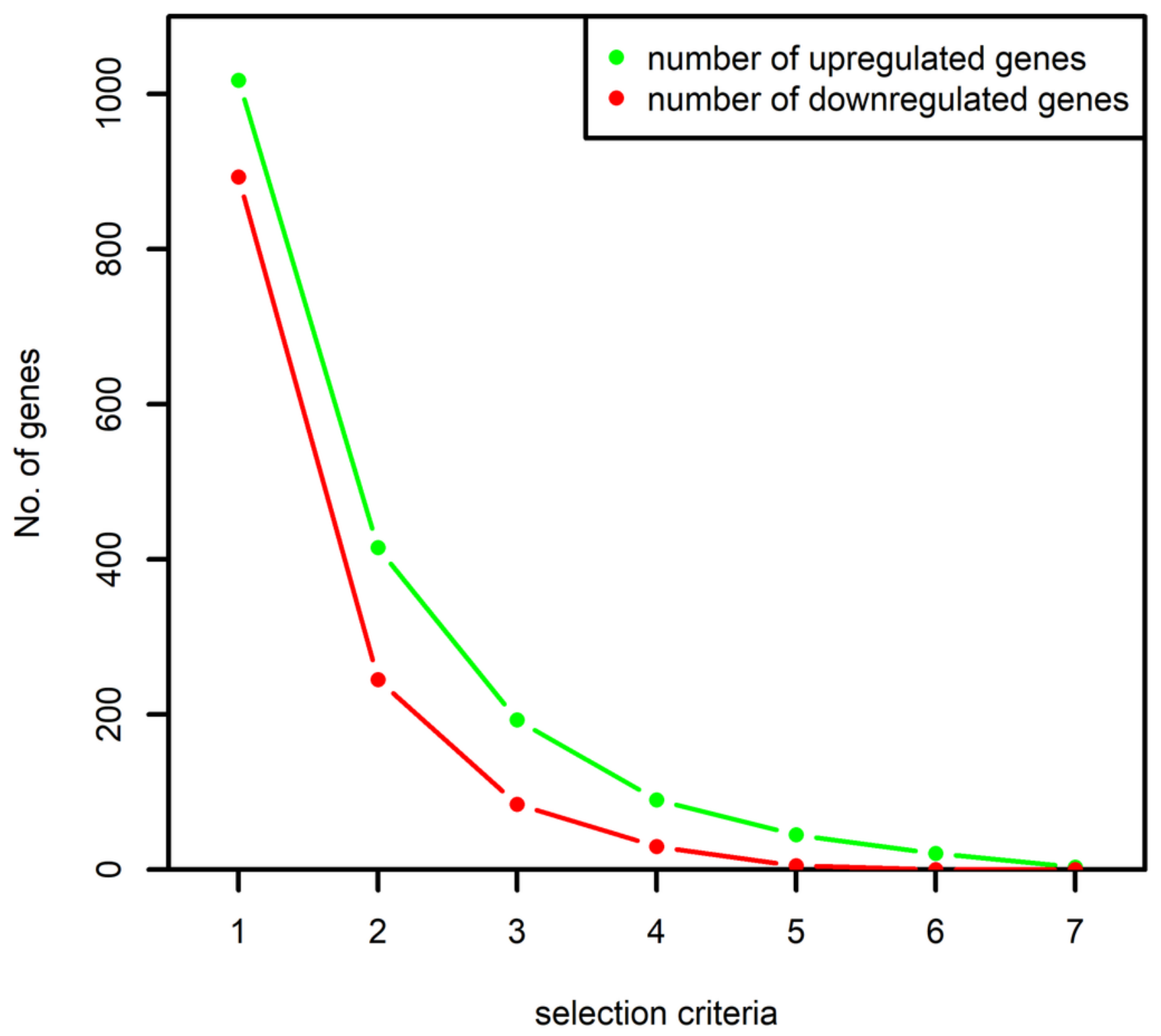


Figure 3

Number of up and downregulated genes shared by pairs of pathways.

The numbers on $x$-axis represent the sum of all the genes belonging to the pathway pairs.

The $y$-axis represents the number of up and downregulated genes common to the pairs. The pathway pairs sharing at least 5 up or 5 downregulated genes are used in this study.

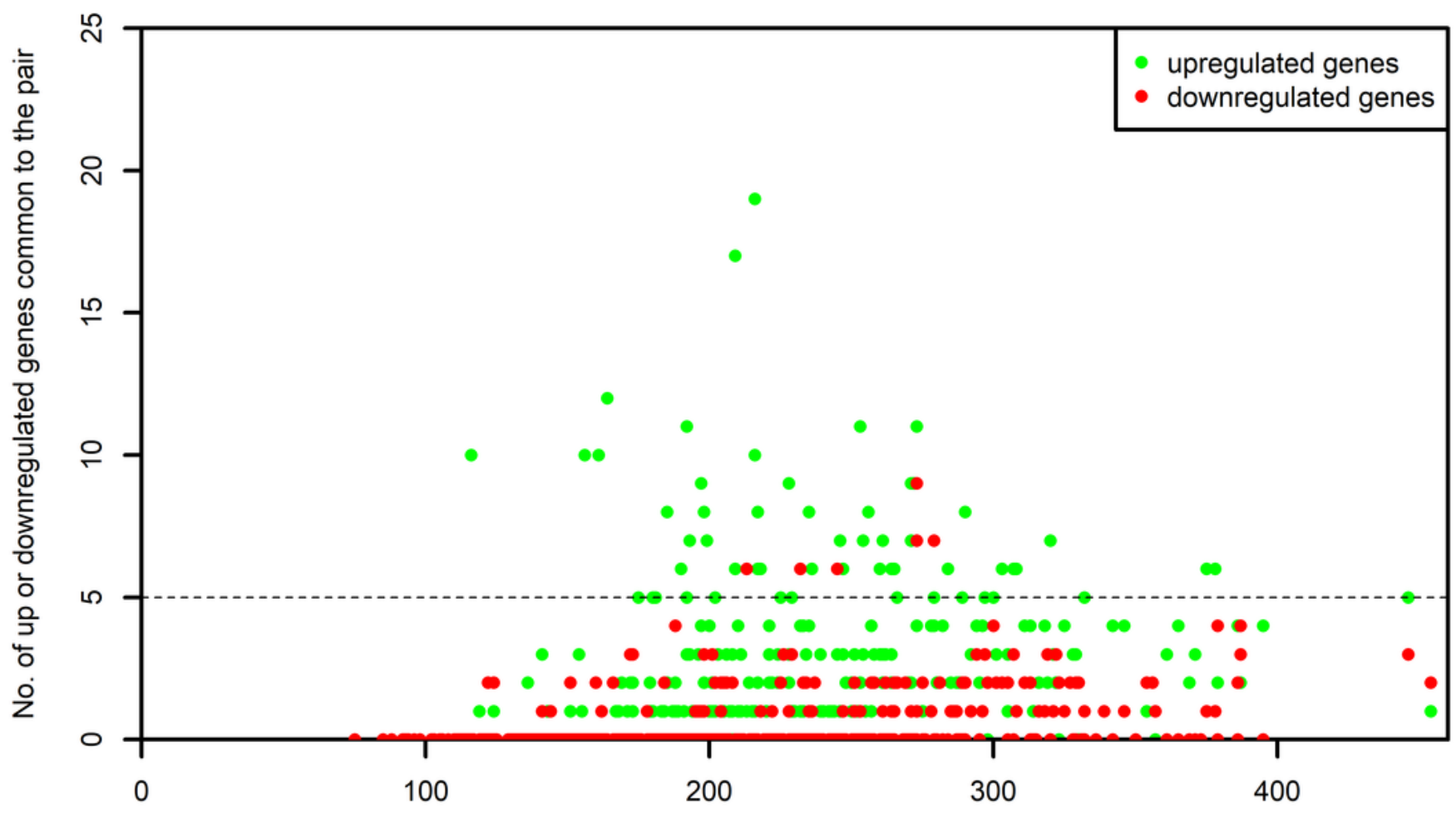

Total number of genes in a pair of pathway 
Figure 4

The KEGG category-wise distribution of the enriched pathways in the upregulated genes of the RA synovium.

The $x$-axis represents the KEGG categories as listed in the KEGG database whereas the $y$-axis denotes the number of enriched pathways from our study belonging to the KEGG categories.

\section{Category-wise distribution of upregulated KEGG pathways}

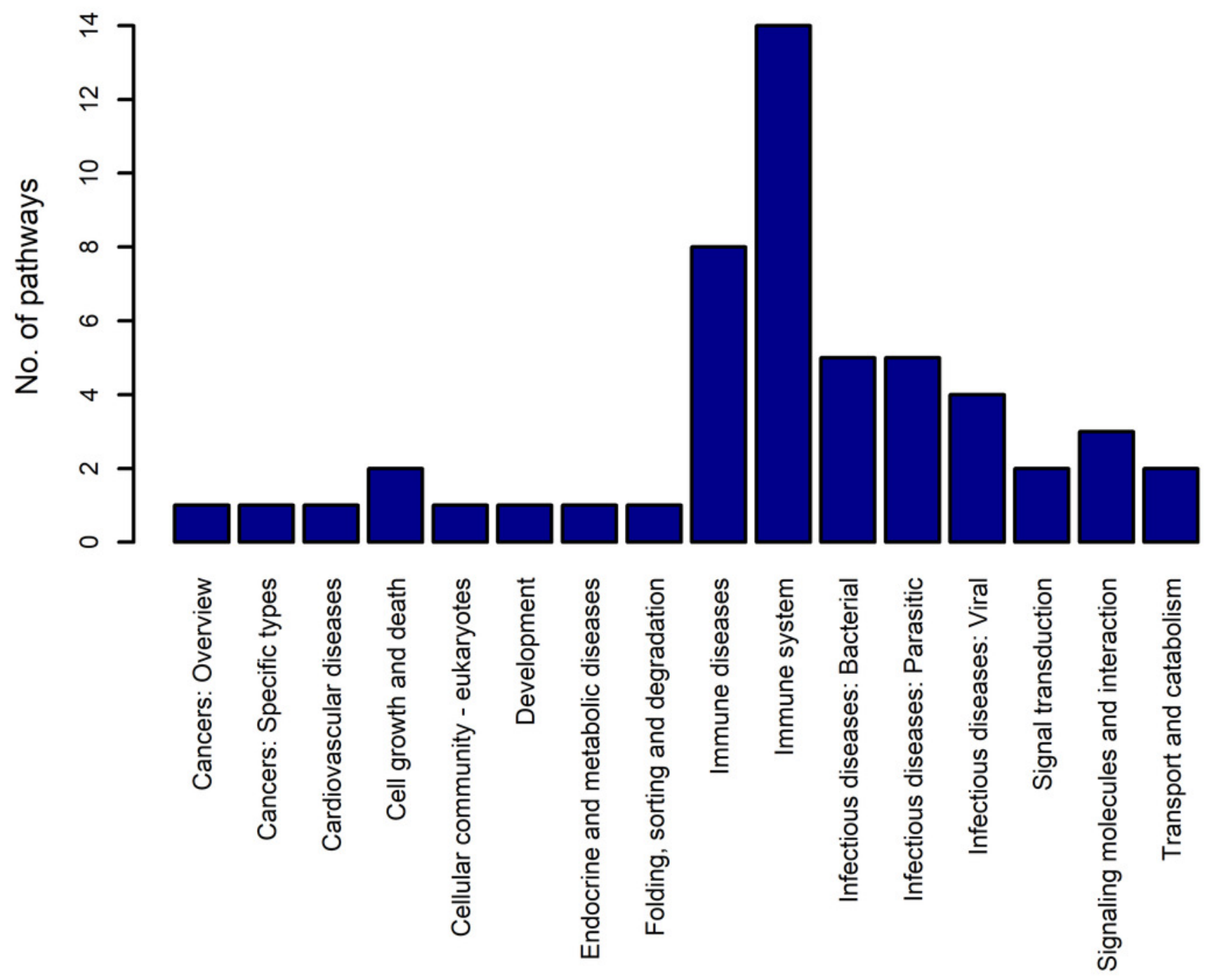




\section{Figure 5}

The KEGG category-wise distribution of the enriched pathways in the downregulated genes of the RA synovium.

The $x$-axis represents the KEGG categories as listed in the KEGG database whereas the $y$-axis denotes the number of enriched pathways from our study belonging to the KEGG categories.

Category-wise distribution of downregulated KEGG pathways

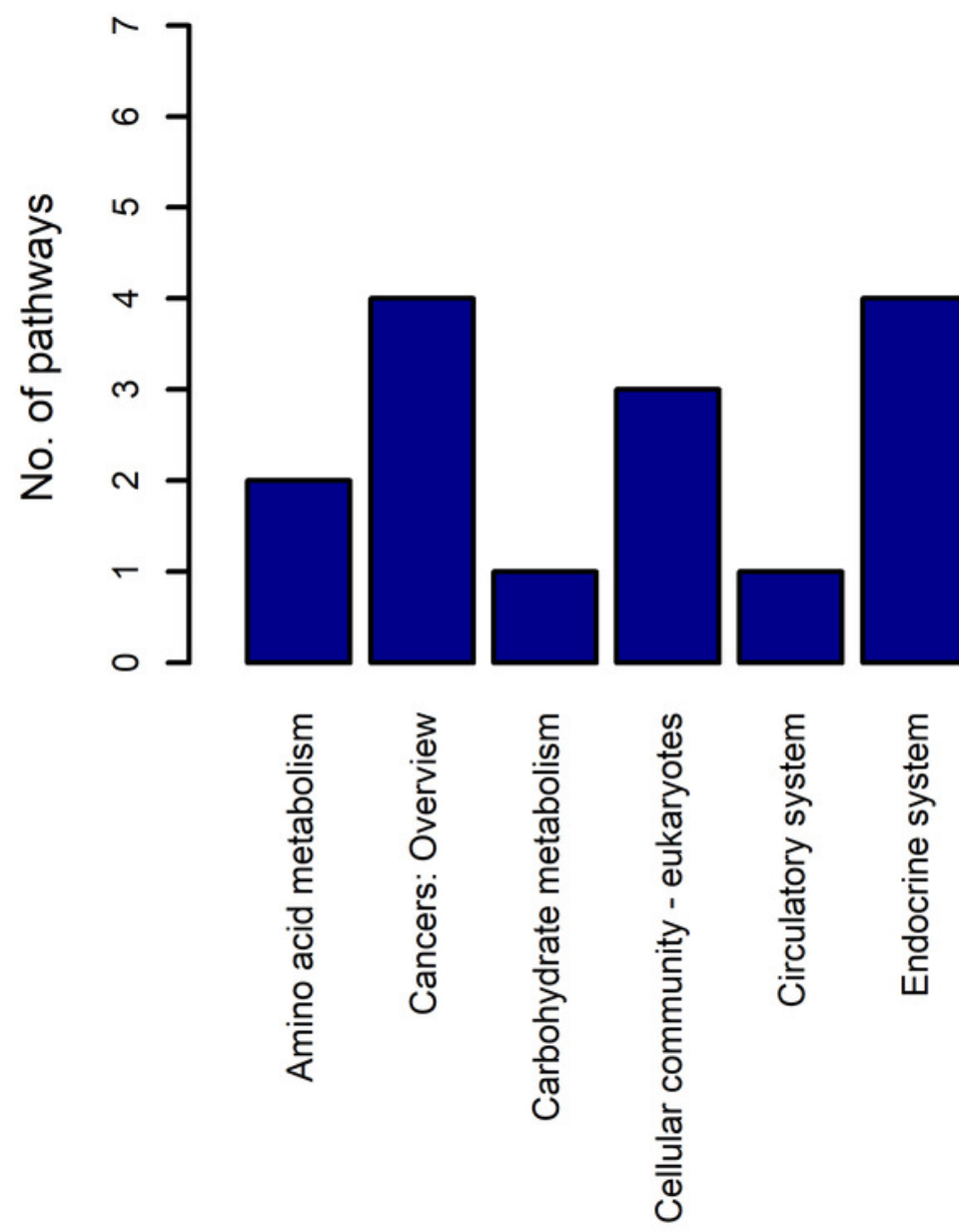

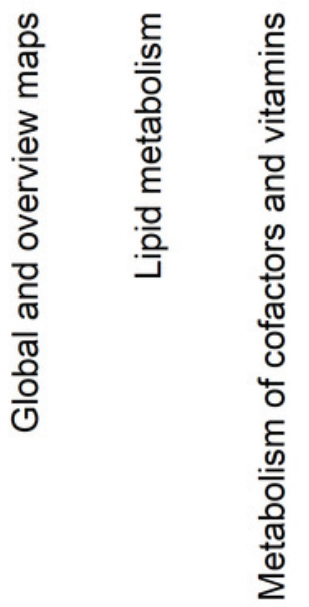

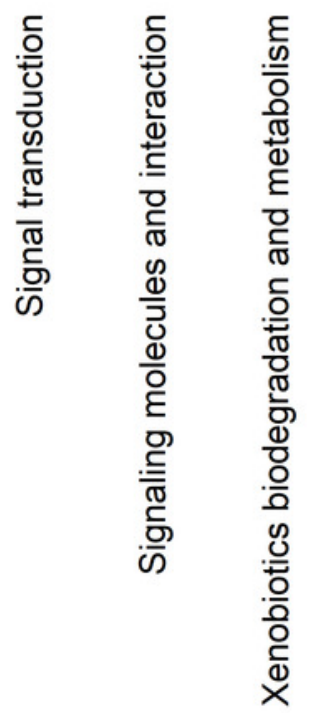




\section{Figure 6}

The interaction network of overlapping pathways.

The blue and red pathway nodes denote the process and the signaling pathways respectively. The white pathway nodes denote the other non-disease pathways. The connection between the pathway nodes represents sharing of at least five upregulated or five downregulated genes by the pair of pathway nodes. The size of the node represents the number of genes present in the pathway. Larger nodes show pathways having more number of genes, and smaller nodes represents pathways with lower number of genes.

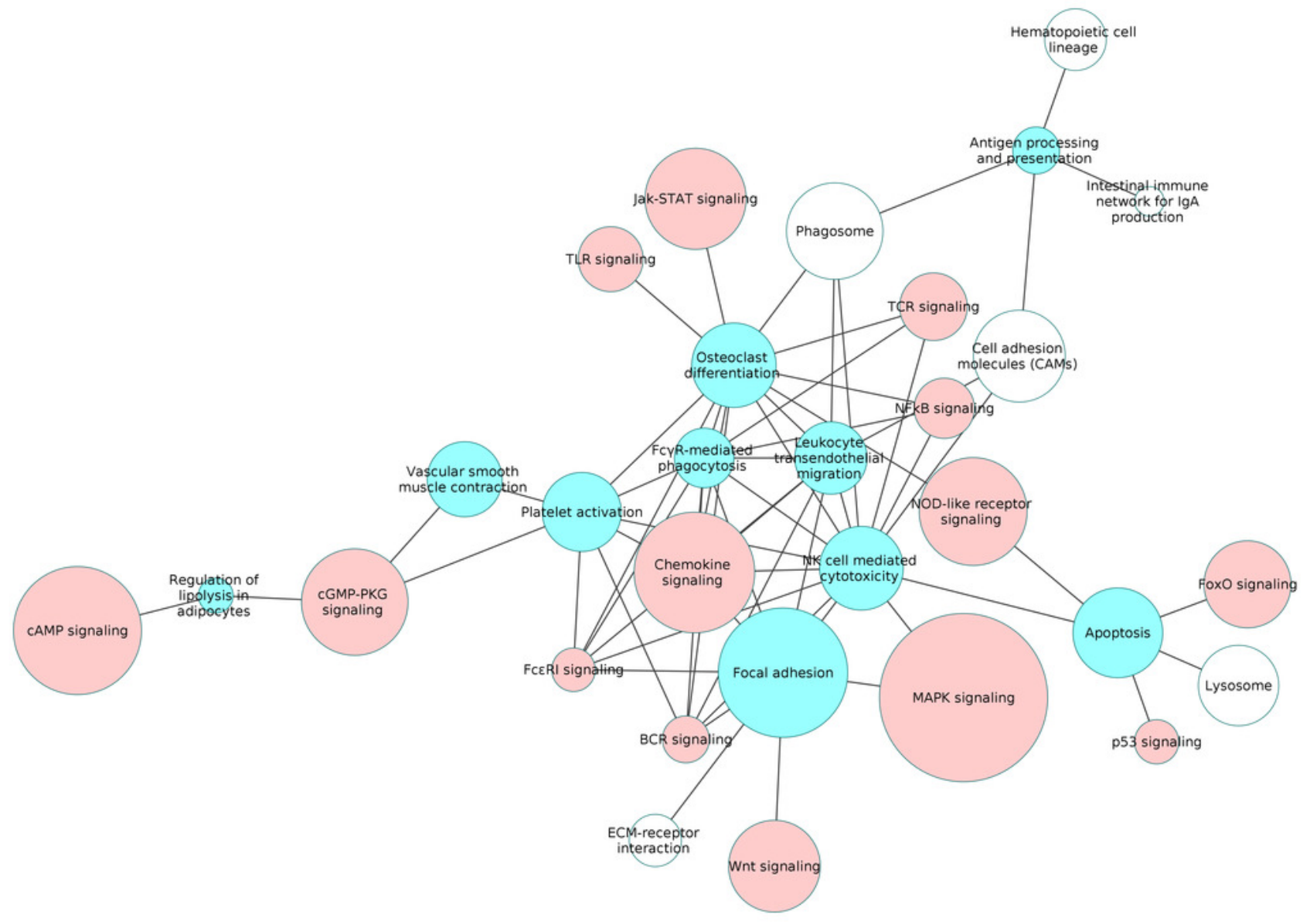




\section{Figure 7}

Overlap analysis of the upregulated process pathway osteoclast differentiation with other enriched non-disease pathways in the RA synovium.

The $x$-axis represents the enriched non-disease pathways with which the osteoclast differentiation pathway share DEGs. The $y$-axis denotes the number of DEGs shared between the osteoclast differentiation pathway and each of the enriched non-disease pathways. Upregulated signaling pathway genes are shown in light blue and upregulated non-signaling pathway genes in dark blue. The pathway osteoclast differentiation does not share genes with downregulated pathways. 


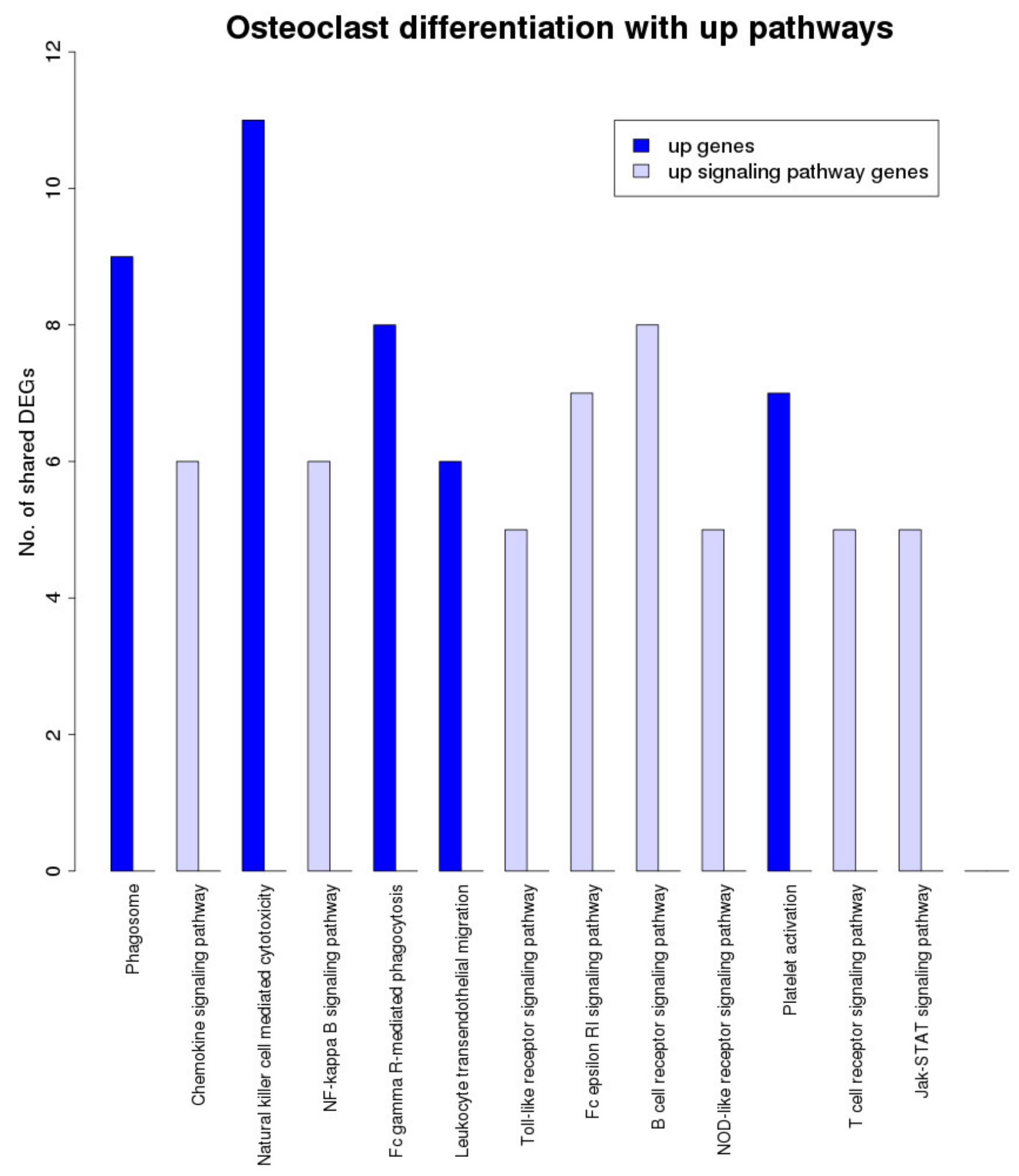




\section{Figure 8}

Overlap analysis of the enriched downregulated process pathways in the RA synovium.

The $\mathrm{x}$-axis represents the enriched non-disease pathways with which the downregulated process pathways share DEGs. The $y$-axis denotes the number of DEGs shared between the downregulated process pathways and each of the enriched non-disease pathways.

Downregulated signaling pathway genes are shown in light pink and downregulated nonsignaling pathway genes in red. (A) Number of DEGs shared by the pathway "Regulation of lipolysis in adipocytes" with downregulated pathways. (B) Number of DEGs shared by the pathway "Vascular smooth muscle contraction" with upregulated pathways. (C) Number of DEGs shared by the pathway "Vascular smooth muscle contraction" with downregulated pathways.

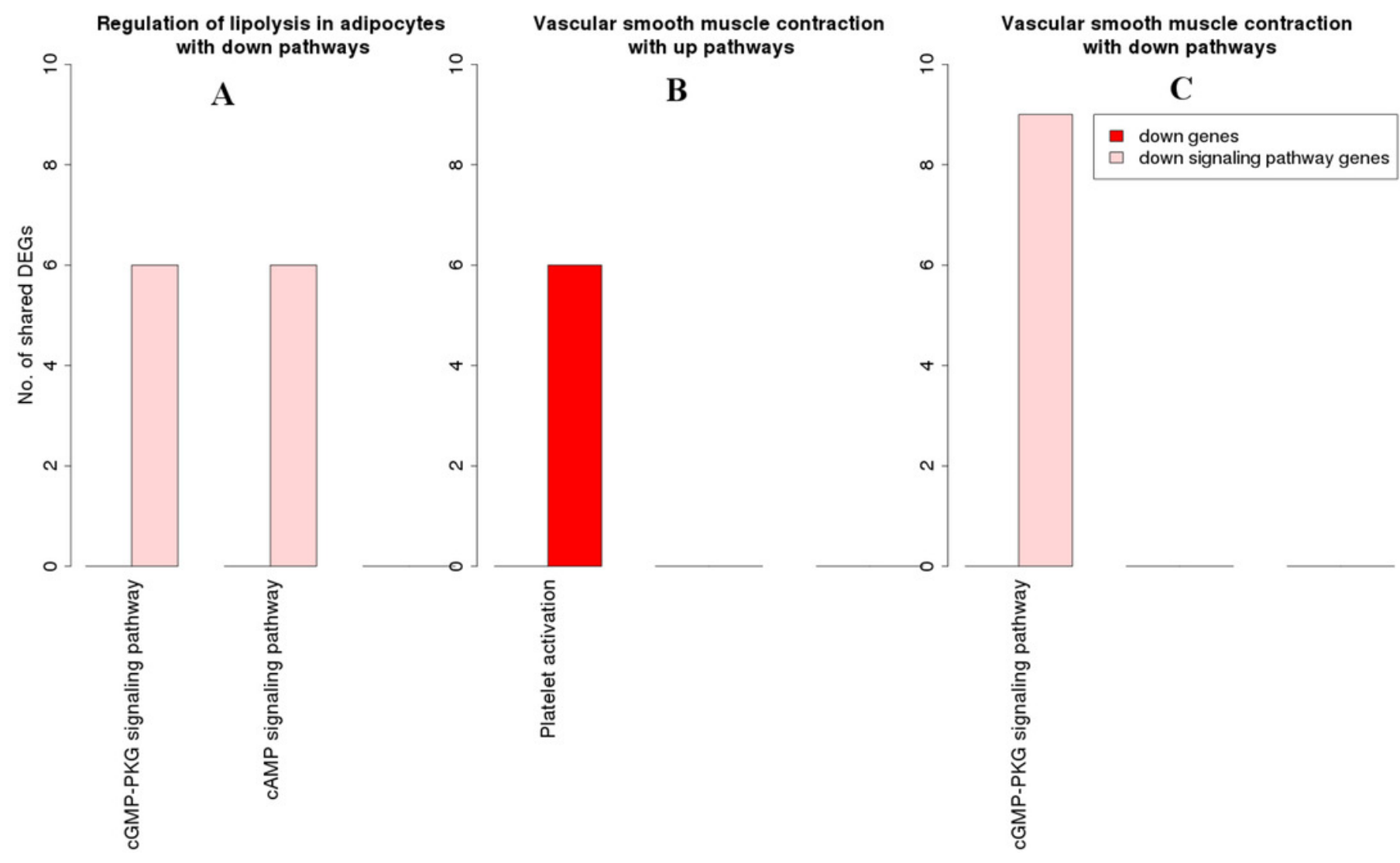




\section{Figure 9}

Activation of NF- KB proteins in the osteoclast differentiation network.

The core proteins are represented by thick borders and the shell proteins by thin borders. Rectangle nodes represent the DNA-binding proteins. The RA drug targets are indicated by red borders. The degree of differential regulation of the nodes is denoted as follows: red to grey - downregulation and green - upregulation. The edges of PRKCB are included from literature.

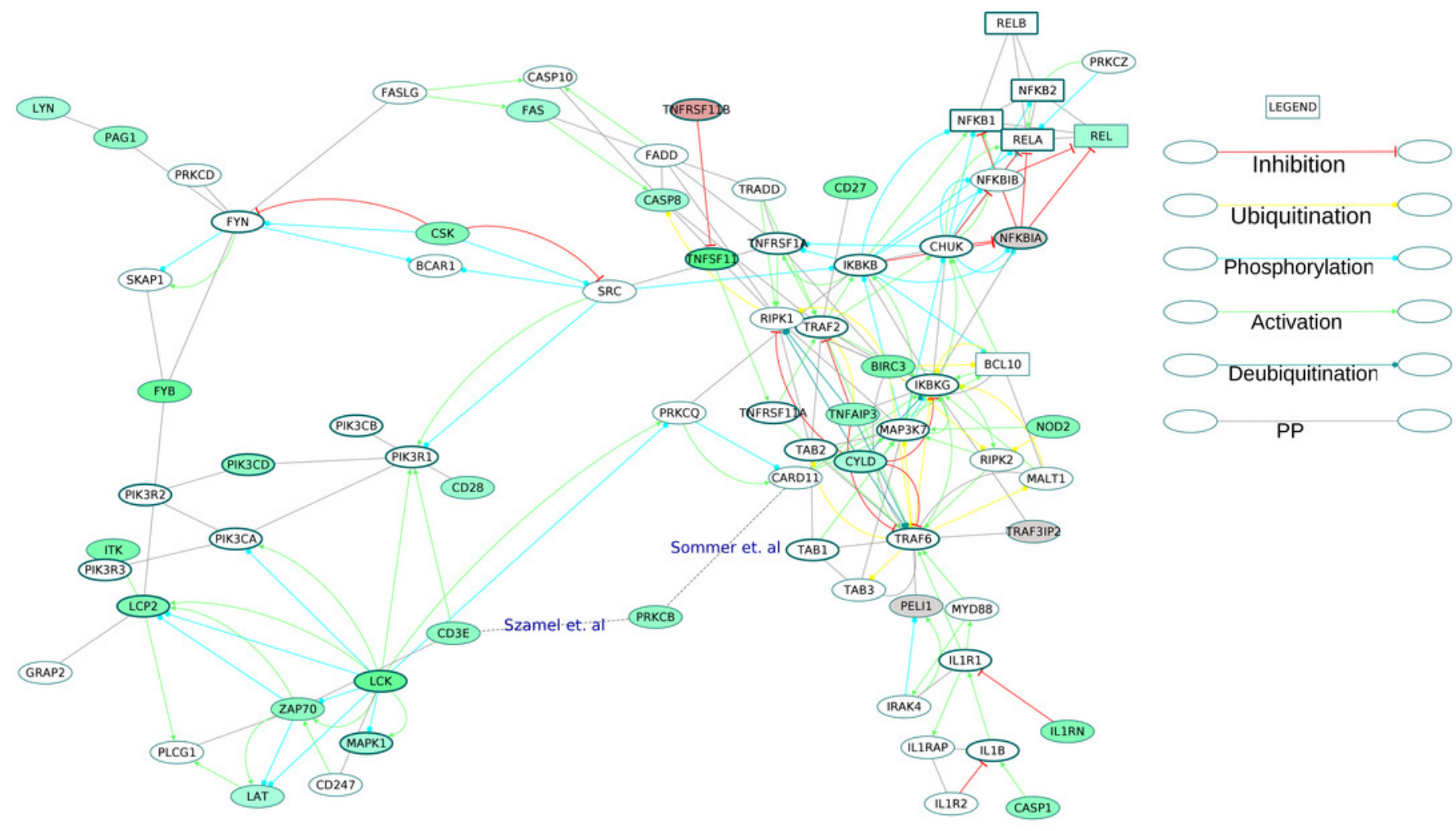




\section{Figure 10}

A schematic of enhanced ROS production mediating differentiation of osteoclasts in the RA synovium.

The degree of differential regulation of the nodes in the RA synovium is denoted as follows: red - downregulation and green - upregulation. The cytokine (TNFSF11) and the membrane receptors (CSF1R and CD3E) are above the horizontal line. Genes corresponding to the Nox2 complex and the Forkhead Box proteins are within rectangular boxes. The colors of the edges denote the following: green - activation, red - inhibition, blue - phosphorylation and black PP. The dotted edges represent the interactions which involve other intermediate molecules. The inhibition of Forkhead box proteins by TNFSF11 are included from literature.

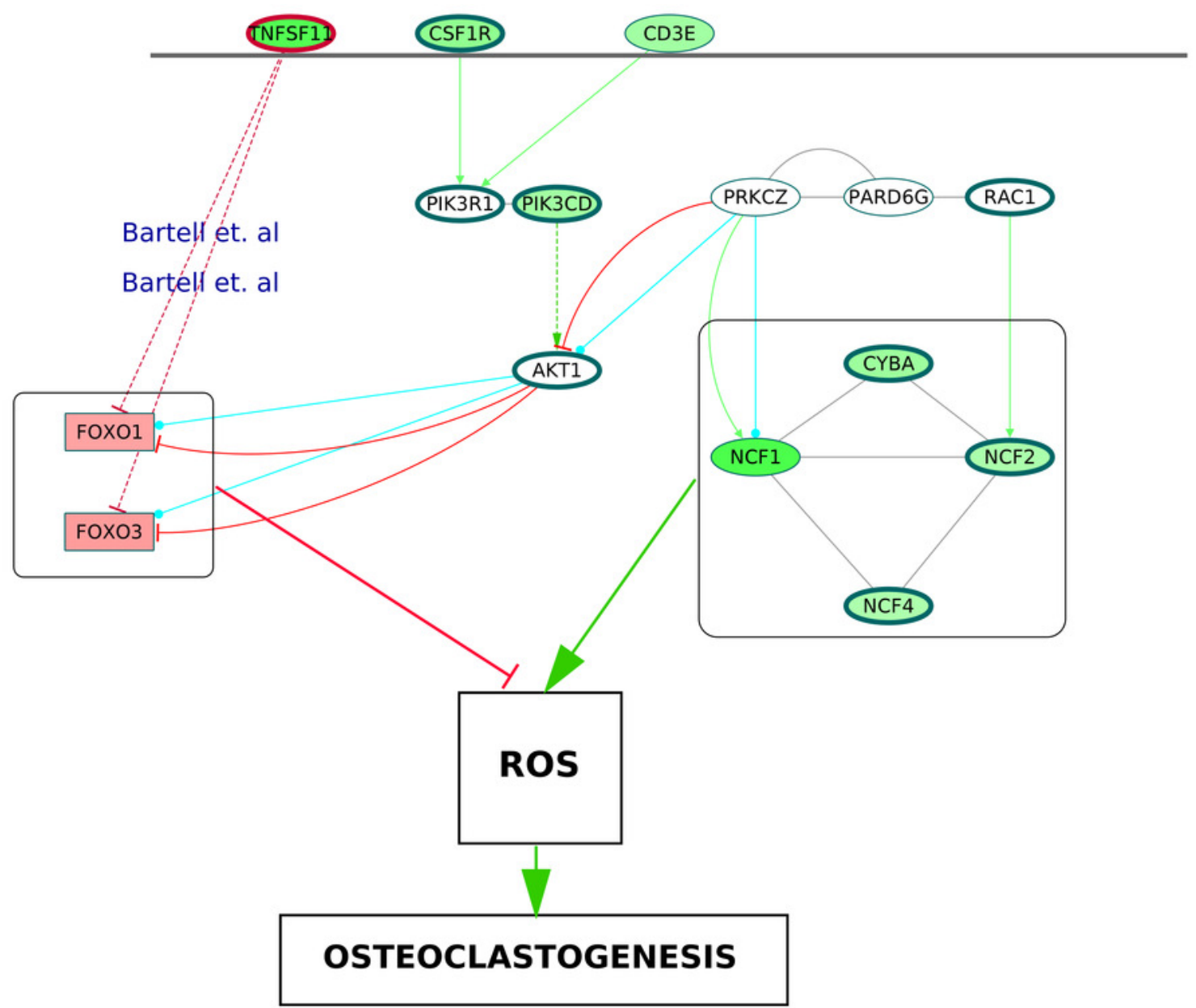

